\title{
Hibridaciones de saberes y lógicas culturales en la pesca: vivir de la mar y en la mar en Andalucía (España) y Chiloé (Chile) en el contexto contemporáneo
}

\section{Hybridations of knowledge and cultural rationalities in fishing: living of the sea and at the sea in Andalucia (Spain) and Chiloe (Chile) within present day context}

\author{
David Florido del Corral ${ }^{1}$ https://orcid.org/0000-0003-1908-5756 \\ ${ }^{1}$ Universidad de Sevilla, Sevilla, ESPAÑA. Email: dflorido@us.es
}

\begin{abstract}
Resumen
Los procesos de construcción de conocimiento de los pescadores de distintos puertos de Andalucía (sur de España), enmarcados en la diversidad de modos de apropiación material e intelectual del territorio marino, son el objeto de este trabajo. Haciendo uso de distintos conceptos que pertenecen a los giros posestructuralista y ontológico en la antropología, se quiere explicar los modos cognitivos relacionales que vinculan los polos de Naturaleza y Cultura, hasta difuminar sus límites (“Culturaleza”). El análisis se articula en tres grandes ejes: comunalidad, relacionalidad y el papel de los artefactos tecnológicos en esas tramas relacionales. Una vez precisados los rasgos básicos de este hacer-pensar-ser, planteo la aplicación de un modo de mirar basado en hibridaciones culturales, para entender tanto dinámicas económicas en distintos contextos del sur de Chile como una propuesta de gestión basada en el diálogo de sus formas de conocimiento del medio, con los dispositivos técnicocientíficos que sirven para definir la política de ecosistemas marinos por la Administración. De este modo centramos el debate en hibridaciones de prácticas y saberes, y sus posibles consecuencias en los ámbitos económico y político.
\end{abstract}

Palabras claves: antropología de la pesca, conocimiento ecológico tradicional, giro posestructuralista, giro ontológico, hibridaciones culturales.

\begin{abstract}
The goal of this paper is to reflect upon the processes of knowledge construction of Andalusian fishermen (Southern Spain), linked to diverse forms of material and cognitive appropriation systems of marine environment. Making use of a set of anthropological concepts embedded in the post-structuralist and ontological turns, I seek to explain the relational modes -both practical and cognitive, that link organically the poles of Nature and Culture, so that their limits are dissolved (Naturo-cultural relationships). The analysis is based on three main axes: community, relationality and the role of technological artifacts in these relational webs of knowledge. After this conceptualization, it is discussed whether we could consider this cultural model as an ontology, in particular its forms of environmental knowledge. Finally it is proposed to reorient the normative systems of fisheries management, promoting a dialogue: on one hand, between the traditional and scientific knowledge; on the other hand, between artisanal/traditional patterns and industrialized and market economies at the Southern coast of Chile. Thus, the focus is placed on the hybridization of practices and knowledge, as well as on the consequences of their combinations in the political and economic fields.
\end{abstract}

Keywords: anthropology of fishing, ecological traditional knowledge, post-structuralism, ontological turn, cultural hybridations.

Recibido: 20 julio 2017. Aceptado: 16 marzo 2018 


\section{Introducción}

Me propongo reflexionar sobre la aplicación de diversas categorías conceptuales que surgieron desde los ańos ochenta en adelante sobre las relaciones entre grupos humanos y sus contextos socionaturales: primero, a partir del giro posestructuralista, a continuación, mediante la revisión que ha tenido lugar a posteriori, a través de lo que Blaser (2009) bautizó como "giro ontológico". El primer objeto de estudio son los procesos de construcción del conocimiento sobre un entorno a partir de un variado conjunto de pesquerías del sur de la península ibérica. Almadrabas, ${ }^{1}$ corrales de pesca ${ }^{2}$ y otras modalidades de pesquerías, tanto de pequeña escala como otras más tecnificadas, aportarán el material etnográfico para este objeto de reflexión.

La potencialidad de este programa de investigación radica en que permite la incorporación y/o el redescubrimiento de categorías de análisis que habían quedado en un segundo plano en las aproximaciones comunes en la antropología de la pesca (Galván y Pascual, 2016). En particular, me pregunto si entre las pesquerías -especialmente, pero no de modo único, en las artesanales- se puede vislumbrar una teoría, una cosmovisión, a partir de categorías como "comunalismo"o "relacionalidad". También es necesario analizar el papel que juegan en estas cosmovisiones tanto sistemas tecnológicos tradicionales (basados en capacidades humanas) como los dispositivos tecnológicos que se han ido incorporando a las flotas desde los años ochenta a esta parte, de un modo generalizado. El punto de partida es que la praxis y cosmovisiones asociadas que los pescadores ponen en marcha (un hacer-conocer-explicar indisociables) se caracterizan por una conexión entre seres humanos y animales y otras entidades del entorno,

1 Arte pasivo consistente en disponer un entramado de redes en puntos próximos a la costa, para capturar atunes (Thunnus tynnus) y otras especies, cuando realizan sus migraciones anuales de carácter gamético, entre abril y junio (hacia el mar Mediterráneo). En la costa atlántica andaluza quedan cuatro.

2 Estructura semicircular, a base de piedras locales, para cercar espacios intermareales donde capturar distintas especies de pescados, moluscos y crustáceos. Están situados en el entorno de la desembocadura del río Guadalquivir. entes vivientes y no vivientes, artefactos tecnológicos y "cosas", entendidos como "actantes" de diversa "naturaleza" que, puestos en conexión, producen distintos y distintivos modos de relaciones humanoambientales (podríamos decir 'culturalezas', si se nos permite el neologismo).

Sin embargo, la reflexión que propongo aquí no se detiene en la elucidación de esas formas de construir el mundo, sino que pretende iniciar un debate ulterior. Aquí se abre un horizonte de reflexión diferente, que nos obliga a plantearnos la capacidad que tienen las pesquerías (entendidas como sistemas de apropiación material, política y cognitiva "en" el ecosistema marino) para adaptarse a distintos marcos geoeconómicos y geopolíticos. En este punto, incluiré información sobre pesquerías del sur chileno para explorar hibridaciones entre lógicas culturales diversas (las que responden a un modelo más tradicional frente a las que irrumpen de la mano de la globalización tecnológica y económica), abriendo una perspectiva comparativa que permita imaginar hasta qué punto los resultados del trabajo de campo en el sur de España son aplicables a otros enclaves. Sugiero a continuación la necesidad de repensar los modelos científico-políticos que sustentan desde el Estado la política pesquera -con el auxilio fundamental de la bioeconomía y ecología marinas-, mediante la incorporación de los saberes locales, vernáculos, de aquellos que viven "en" la mar. ${ }^{3}$ Se trataría de romper la disyunción entre los sistemas expertos que están en la base de gestión "de" la pesca y los modos vernáculos surgidos "en" los socio-ecosistemas marinos (García Calvo, 1979). ${ }^{4}$

3 En Andalucía, en los ámbitos pesqueros, 'mar' es sustantivo referido en femenino comúnmente. Usaré esta forma cuando quiera enfatizar la perspectiva interna, desde los contextos culturales locales.

4 El juego de las preposiciones de/en recupera una dicotomía elaborada por Agustín García Calvo (1979) para explicar los modos discursivos de construir el mundo social ('mundo 'en' que se habla/ mundo 'del' que se habla). El mundo en que se habla es el de los deícticos, de las relaciones personalizadas, al alcance de nuestra mano, manos con las que construimos intersubjetivamente nuestro universo; mientras que el "mundo del que se habla” es el resultado de un relato, abstracto, construido por ideas y categorías, presuntamente objetivo (tiende irrevocablemente a ello), manipulable también pero desde una agencia externa, con fines 


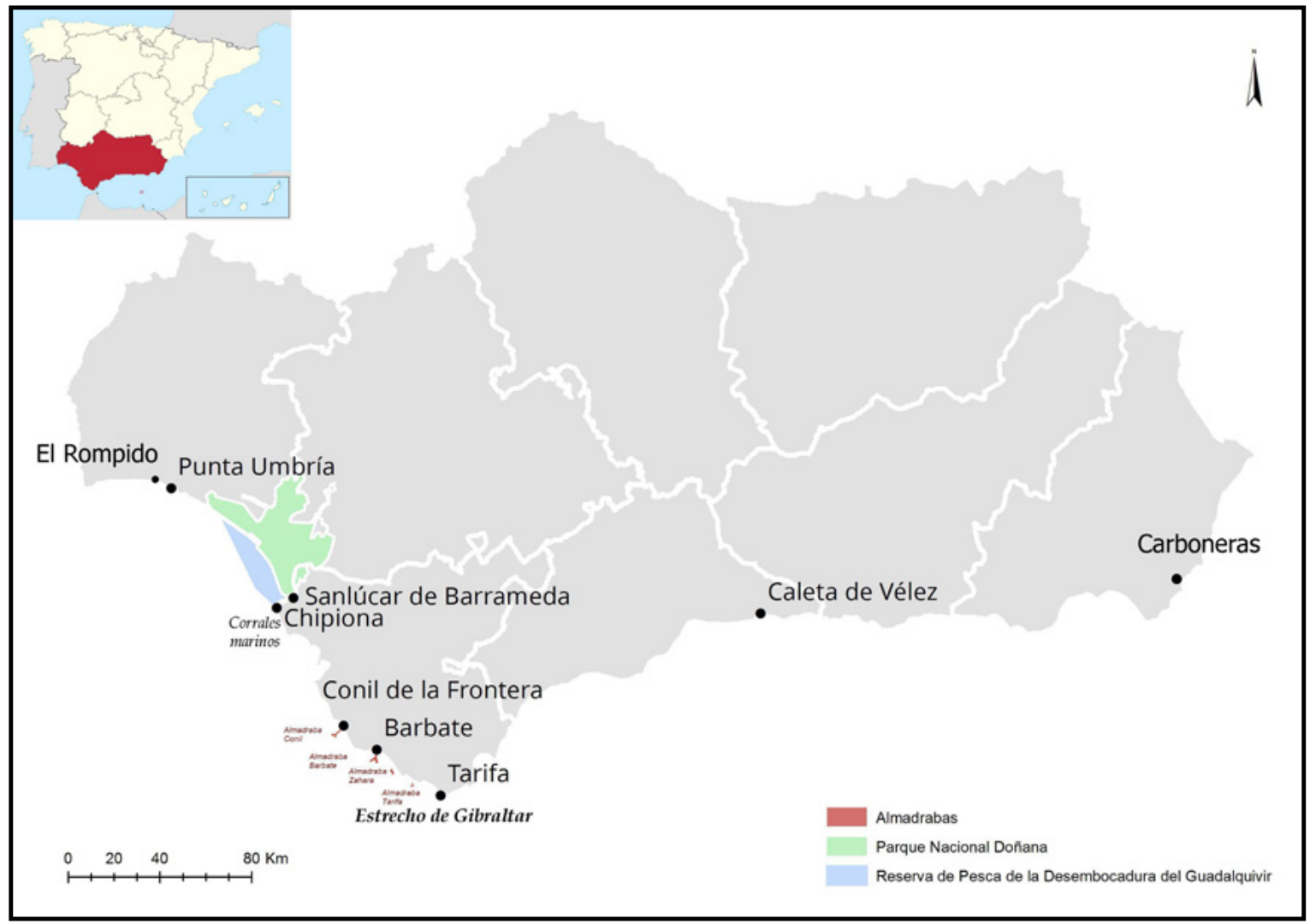

Figura 1. Mapa de Andalucía, con indicación de puertos y territorios mencionados en el texto Fuente: Elaboración propia.

El material etnográfico procede de tres contextos diferentes: observaciones realizadas en distintas pesquerías andaluzas (Figura 1); entrevistas en profundidad con el objeto de indagar sobre los modos de conocimiento de los pescadores; y participación en encuentros con pescadores y científicos desarrollados en los dos últimos ańos (2016-2017), en el marco de proyectos de transferencia del conocimiento. ${ }^{5}$ Mi intención es "crear las condiciones bajo las cuales uno puede ver cosas en sus datos etnográficos que, de otro modo, nunca hubiera visto" (Holbraad, 2014, p. 131), convirtiendo la etnografía en la fuen-

estratégicos explícitos, instaurados desde fuera del mundo al que se dirige.

5 Ver el apartado de agradecimientos para la identificación de los proyectos. En concreto, se han realizado seis talleres y mesas de diálogo entre junio de 2016 y noviembre de 2017 , en relación a propuestas de impulso o renovación de zonas marinas en las que aplicar medidas especiales de gestión, a través de reservas marinas (de interés pesquero), en Andalucía. te de repensar el mundo. Complementariamente, las informaciones referidas a pesquerías chilenas proceden de bibliografía especializada que se centra en la importancia de las cosmovisiones asociadas a los modos de vida de la pesca artesanal y las formas de combinación de su saber-hacer con las recientes dinámicas de globalización económica e industrialización, ya sean la intensificación de determinadas producciones de moluscos o algas, la exposición a una emergente actividad turística, ya la explosión de la salmonicultura en el maritorio de Chiloé.

\section{Perspectiva teórica}

Para esta aproximación utilizo distintas herramientas teóricas: por una parte, el giro posestructuralista nos puede servir para repensar los modos cognitivos de construir el mundo de los pescadores: el agenciamiento de Deleuze y Guattari (2004); la teoría del actor-red de Callon (1995), Latour (1992) y Law 


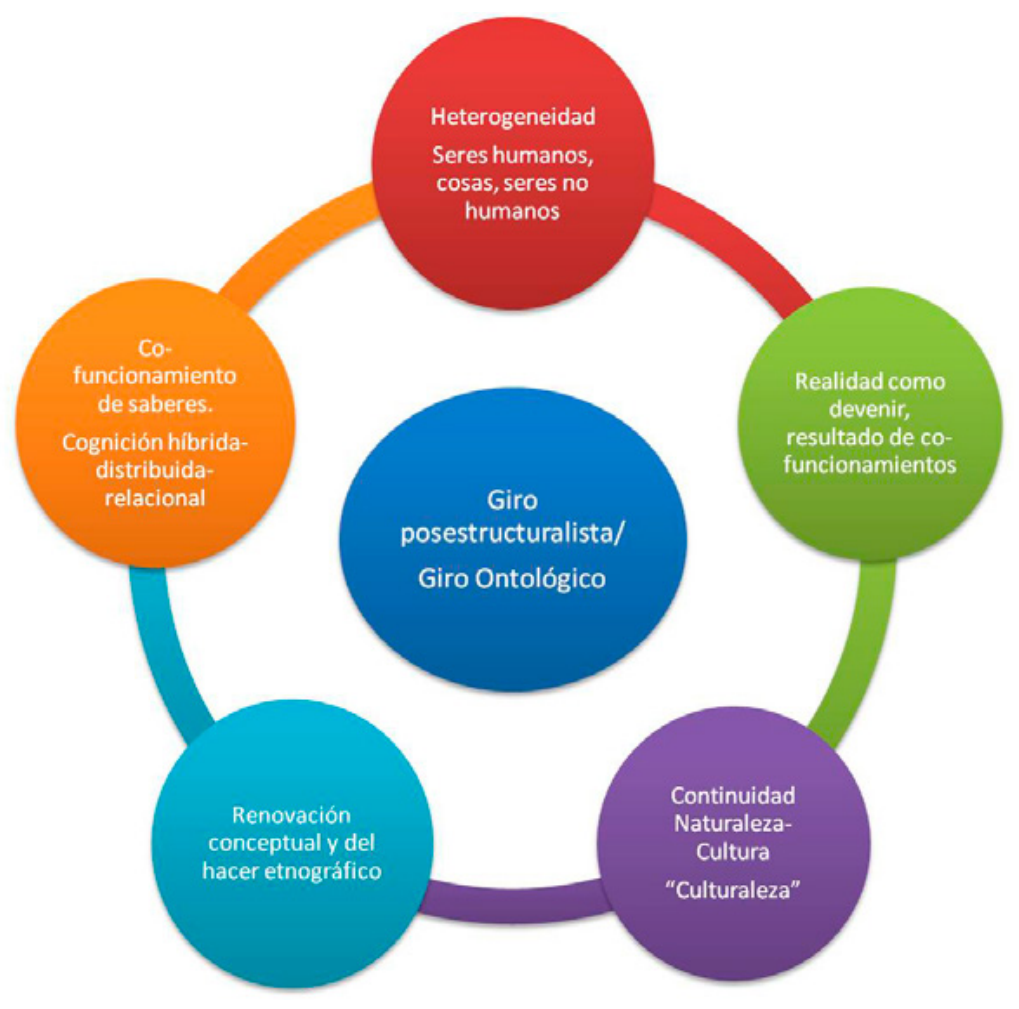

Figura 2. Conexiones entre los giros posestructuralista y ontológico. Fuente: Elaboración propia.

(Law y Mol, 1995); las ontologías de Descola (2005, 2012), los modelos de relaciones humano-ambientales de Pálsson (2001) o el modelo de cognición híbrida y distribuida de Varela (Varela et al., 1992) o Clark (1999), entre otros. Por otra parte tenemos la ontología política auspiciada más recientemente por Blaser (2009). Entiendo que esta nueva perspectiva nos permite superar el debate de los significados para resituarlo en el campo político, en el combate por los modos de existencia, permitiendo así plantear preguntas sobre la política de los ecosistemas marinos y la supervivencia de esos modos de vida en un entorno cambiante que está dominado por la eficiencia económica, política o científica (Latour, 2005), especialmente en entornos que reciben procesos de intensificación de capital, tanto para transformar los modos productivos como las relaciones de comercialización. Nuestro interés es salvaguardar la integridad y la coherencia entre esos postulados, a pesar de su heterogeneidad, para avanzar hacia la discusión que más nos interesa: plantear si los pescadores, a partir del caso andaluz, han desarrollado históricamente una cosmovisión, asentada en sus formas de apropiación material del mar, que pueda tener resultados en los modos de gestión. Siguiendo a Reynoso, no se trata tanto de aplicar una metodología creada por alguno de estos diversos programas de investigación, sino de "integrar lo más valioso de sus observaciones en el trabajo empírico” (2017, p. 248). ${ }^{6}$

Mi propuesta parte de la posibilidad de integrar estas distintas perspectivas teóricas, a partir de los hilos de

6 Este trabajo de Reynoso (2017) es particularmente crítico con el conjunto de líneas de pensamiento que podrían encuadrarse bajo las etiquetas de perspectivismo o posestructuralismo (Descola, Viveiros de Castro, Latour, Deleuze y Guattari, Strathern o Roy Wagner). El tono especulativo de estas aportaciones, la ausencia de un programa metodológico replicable, el apropiarse de herramientas y conceptos de otros campos del saber científico sin la solvencia exigida, o la tendencia a crear categorías y conceptos que ya estaban presentes en autores anteriores, son las principales debilidades señaladas. 
continuidad existentes entre ellas (Figura 2): i) La apuesta por la heterogeneidad (entre los sujetos y los objetos; los seres humanos y los no humanos; los sujetos y los sistemas sociales; los símbolos y las acciones sociales, de lógicas culturales...). ii) La realidad, de este modo, nunca se da por existente, sino que es siempre el resultado de modos de cofuncionamiento entre distintos artefactos que deben ser explicados según el principio de simetría de Callon o Latour: discursos con sus significados, prácticas relacionales, objetos máquinas, seres no humanos..., todos urdidos en relaciones complejas de co-laboración que van tejiendo un espacio de virtualidad tanto en el orden natural como el social, de donde surge el término "culturaleza" o "naturocultura" (Haraway, 2016). ${ }^{7}$ iii) Todas estas aproximaciones comparten también su vocación de repensar el mundo a partir de nuevas categorías de análisis, en tanto que las nociones bien asentadas en la sociología previa se han vuelto inservibles o limitadas.

No puede perderse de vista que, para evitar los riesgos de un análisis esencialista de los pescadores, entiendo la cultura no sobre categorías de integridad, unidad y distintividad. No existe tal cultura entre los pescadores, sino modos de ser-hacer-sentir-pensar en el mundo que se van reconstituyendo en marcos cambiantes, formando parte de procesos políticos, sociotecnológicos, económicos y ecológicos de amplio alcance. Esto es, para evitar cualquier inercia de reificación de modelos culturales, parto del supuesto de que las sociedades se tiñen de distintas lógicas y racionalidades culturales, que se reproducen de modo articulado y/o conflictivo. Si bien existe un marco global en que las relaciones de mercado y estrategias políticas para promover su dominio están a la orden del día, otras formas de hacer y pensar el mundo no han sido eliminadas, sino que se producen hibridaciones de distinto signo, construyendo nuevos tejidos culturales (García Canclini, 1990; Friedman, 1996; Escobar, 1999; Gudeman, 2001). Esta perspectiva será aplicada en la última parte del artículo.

7 Yo prefiero "culturaleza" - que ya había usado para este texto antes de leer el nuevo Manifiesto de Harawayporque prioriza la capacidad humana de construir su entorno, aunque en cofuncionamiento, mediante dispositivos y relaciones, tanto ecológicas como fruto de la producción de la ingeniería humana.

\section{Modos de ser-saber-hacer de los pescadores andaluces}

En un testimonio publicado en 1930 en una revista de y para pescadores, en Barbate (Cádiz), puerto muy próximo al estrecho de Gibraltar, se narraba este sistema de navegación:

Para navegar de Zahara a Barbate no hacía falta saber leer ni escribir, bastaba con ser pescador para llegar a la barra [puerto], aunque fuera cerrado de niebla; yo recuerdo que cuando esto ocurría mi padre se metía debajo de la proa y, con el oído atentamente escuchando el ruido que hacen las piedras del fondo, mandaba a poner el rumbo que necesitaba justamente para llegar a la barra [...]; era un procedimiento tan natural que la mayor parte de las veces se mandaba a los chiquillos a que lo hicieran por tener menos fuerza para el remo" (La Independencia de Barbate, 1930, núm. 22, p. 3).

Casi noventa años después, en la primavera de 2017, un armador de arrastre en la bahía de Caleta de Vélez (Málaga, costa mediterránea de Andalucía) me explicaba cómo se representaba los fondos, desde el barco, con los nuevos equipos tecnológicos:

No te hace falta estar ahi abajo. Para nosotros, la sonda es fundamental, es la que te va diciendo realmente dónde estás, qué territorios $y$ de ahi sabes qué especies te encuentras. Llega un momento en que conoces el fondo marino mucho mejor que el fondo de tierra. Luego ya, empiezan a entrar los aparatos estos, los GPS, el plotter, que te permite el posicionamiento tuyo y de los demás... (S., pescador de arrastre, 40 años).

Quiero decir: me sorprendía observar que entre dos modos de representarse el entorno tan distanciados el uno del otro, por criterios tecnológicos y cronológicos, sin embargo, hubiese hilos invisibles de conexión: bien a través de los sentidos, bien a través de dispositivos técnicos que el pescador usa como una prótesis, este es capaz de "imaginarse" los 
fondos (Sánez Reguart, 1791). ${ }^{8}$ Se ponía de manifiesto que, parafraseando a Descola cuando se refería a la selva (1988), el medio marino es muy culto; esto es, está densamente ocupado a través de prácticas y saberes. Es importante subrayar esta perspectiva, que se enfrenta a la noción arquetípica según la cual el medio marino, para quien no lo conoce, se representa como manifestación pulida de la naturaleza, ya dada, que sigue sus propios mecanismos de funcionamiento, "an independent domain of intrinsic value, truth or authenticity" (Soper, 1996, p. 22). Por el contrario, a través de artefactos "epistémicos", unos biológicos, corporales, otros requiriendo la colaboración hombre-máquina (una tecnología fruto de complejos procesos sociales), logran hacer de la navegación o la pesca una "enacción", esto es, un conocimiento incorporado en el sentido de Varela (Varela et al., 1992), que se va descubriendo en la permanente relación mediante la que construimos tanto la cultura como la naturaleza. Veamos una somera caracterización de esas formas de saber hacer.

\section{Comunalidad}

Con este principio quiero destacar la traducción, de carácter inmediato, que los pescadores utilizan para imaginar el comportamiento de los animales y otros elementos del ecosistema, atribuyéndoles cualidades humanas. En el clásico de Thoreau, Walden (1854), el escritor estadounidense destaca que lo que constituye una experiencia diferencial 'en' el bosque es saberse y sentirse formando parte de los procesos ecológicos que unen a los animales con las plantas y el resto de elementos del entorno. Es en este sentido en el que podemos hablar de comunalidad en el caso de los pescadores profesionales. De este modo se facilita una suerte de continuidad socioecológica entre todos los seres (vivos e inertes, bióticos y abióticos) que conviven dentro del socioecosistema, como queda recogido en la etiqueta

8 Como reconocía, hace más de 200 años, el comisario de Marina Antonio Sáńez, la capacidad de interpretar los fondos marinos, "es la parte más esencial de la ciencia de los pescadores [...]. Estos conocimientos solo pueden adquirirlos mediante una continua y dilatada practica con que se hallan en estado de formar cierta especie de cartas hidrográficas mentales” (Sáñez Reguart, 1791, vol. I, pp. 353-354). "régimen orgánico de naturaleza" de Arturo Escobar (1999). Si tomamos como referencia el "comunalismo" que teoriza Pálsson (2001), ${ }^{9}$ podemos asumir que determinados rasgos que este paradigma atribuye a las formas culturales de sociedades indígenas, campesinas u otras cuyo proceso de modernización se articula con otros regímenes culturales de larga tradición son aplicables al caso de estudio, como pretendo demostrar de aquí en adelante. Ello no implica que, a priori, sean aplicables también los modelos de equilibrio y las relaciones de reciprocidad que el pensamiento latinoamericano ha atribuido a los colectivos indígenas en las relaciones humano-ambientales (Leff, 2014). Los pescadores no son esos "otros", que encarnan cosmologías en las que las relaciones de parentesco, las relaciones sexuales, las relaciones entre generaciones, además de las relaciones con la naturaleza en sus actividades de caza están implicadas, explicadas y representadas en cosmologías holistas. Por tanto, solo atenderemos aquí a las formas de relación de los pescadores dentro del ecosistema del que forman parte.

Un aforismo de un viejo pescador de Barbate (Cádiz) afirma que "es el pescado quien enseña al pescador", lo que implica cierta traducibilidad entre sus comportamientos, sus intenciones, sus dispositivos de conocimiento. La relación entre el sujeto humano y el resto de seres del ecosistema se caracteriza por la continuidad orgánica, ajustándose a la relación maestro-aprendiz (Pálsson, 2001, p. 92). En la misma línea, los testimonios de los pescadores nos devuelven la distinción que Descola (2005) entiende por universal entre interioridad y materialidad, y que, como una estructura cognitiva significante, les permite atribuir a los animales y otros elementos del entorno cualidades ordinariamente atribuidas al alma humana: intención, pulsión comunicativa, inteligencia... En numerosos testimonios recogidos en el trabajo de campo los peces saben, sienten o han aprendido los métodos del pescador para eludirlos. Y, consecuentemente, el buen pescador debe conocer

9 Sociedad y naturaleza constituyendo un oikos indiviso, en un modelo que, por tanto, anula la diferenciación sujeto (sociedad) - objeto (naturaleza). La reciprocidad generalizada es el lenguaje que caracteriza a este modelo, que se distingue de los otros por atributos como el diálogo, la contingencia y la incertidumbre (Pálsson, 2001, p. 91 y ss.). 
estos códigos y actuar para contrarrestarlos. Para los pescadores artesanales de Chipiona (Cádiz), las doradas (Sparus aurata) son los animales más esquivos, los que mejor conocen las trampas de pescador, como se colige por el hecho de que solo pueden ser capturadas en condiciones ambientales muy precisas (de poca luminosidad), que se dan únicamente en algunas épocas del año. "No es que el resto del año no estén, es que ven las redes y saben cómo eludirlas". Entre los almadraberos del estrecho de Gibraltar, hay distintas categorías de atunes: los más "avispados y valientes", que son los que vienen "de cabo a cabo", cruzando desde la costa africana hasta la punta de Tarifa (Cádiz). Estos se distinguen de los que son capturados en las almadrabas previas, más al norte, que, por ser más medrosos, navegan refugiándose en las ensenadas. Esta jerarquía entre los atunes es deducida del hecho de que los tarifeńos alcanzan un peso medio superior (lo que es asociado por el almadrabero a su mayor carácter e inteligencia), respecto de los que alcanzan el estrecho por su orilla norte (Florido, 2018).

En el mismo sentido, las piedras de los corrales de pesca de la costa noroeste de Cádiz (Florido, 2014) están "vivas": es una naturaleza hecha artefacto y un artefacto que se hace naturaleza: esas piedras marinas compactan a través de las colonias de ostiones (Crassostrea angulata) y multitud de pequeńos organismos sésiles. La existencia del corral se convierte entonces en un estabilizador de la costa, promoviendo un nuevo microecosistema que solo es posible gracias al cuidado meticuloso y diario de los mariscadores locales, que lo convierten en una 'culturaleza', un socioecosistema. El mariscador debe lograr que las piedras "respiren", que se ajusten sin materiales sintéticos para que las olas las atraviesen en sus múltiples oquedades -las mismas que sirven de cobijo a crustáceos y otros organismos- sin reventar su estructura. No estamos hablando solo de discurso, de bellas metáforas y tropos para decir las relaciones socioecosistémicas, sino que estos 'decires' están embragados en formas prácticas de construir el entorno local, natural y social. Para este mariscador que trabaja en los corrales de Chipiona (Cádiz), "el pescado tiene mucha habilidad", entonces, hay que atajarlo mediante pequeñas paredes de piedra al interior del corral, "para no darle ventaja".
Los criollos, los peces y moluscos que se han criado marea tras marea, se quedan dentro del corral para escapar de los predadores, el pescado tiene un saber muy grande, sabe que se va a quedar encerrado porque conoce la zona, porque son de aqui, son criollos, que han crecido chicos ahi, pero parece que cuando llegan a una edad, ya ellos saben que los puedes coger, y entonces se salen, como si presintieran que cuando ya tienen un tamaño los puedes coger y se van, dicen: 'no, ya no me quedo, me largo para la mar' [risas] (L., mariscador, Chipiona, 56 años).

Es decir, que el mariscador les otorga a los animales de la zona, no solo un comportamiento diferencial, sino una suerte de aprendizaje que, por lo general, los pescadores dan por supuesto en sus acciones de pesca. Así lo atestigua en el siguiente testimonio:

Los pescaos también se quedan en los aguajes muertos [mareas con pocos grados, que hacen imposible la pesca en el corral], porque saben que nadie los va a coger y se aguantan ahi. A lo mejor entran con la marea de hoy, con cincuenta grados y va para atrás y se va a poner en treinta y cinco, y ellos saben que en esos tres o cuatro dias se pueden estar tranquilamente en el corral comiendo. Ahora, cuando la marea pega el giro para ponerse a sesenta grados, dice... ;Ya estoy fuera! [risas]. ;Hay que ver! 'Que es asi!! [...] (L., mariscador, Chipiona, 56 años).

La continuidad, y traducibilidad, entre los comportamientos humanos y animales, por tanto, están a la orden del día entre los pescadores, y son un rasgo muy extendido entre otros colectivos humanos, en contextos geoculturales muy diferentes, como subraya Mary Douglas: "[E]ntendemos a los animales como si éstos obraran de acuerdo con los mismos principios que nosotros [...] Los animales fueron incorporados en las categorías sociales humanas por una simple extensión a ellos de los principios con que se ordenan las relaciones humanas" (Douglas, 2008, pp. 146 y 151).

Mucha gente se cree que nosotros nos montamos en el barco, tiramos la red y ya está. No. 


\begin{abstract}
Nosotros tenemos que pensar, nosotros tenemos que pensar exactamente cómo piensan los pescados para saber lo que hace ese pescado, qué es lo que come, el porqué, a lo mejor, cuando el pescado lo ves tú más canijo, el porqué ese pescado que come almejas, ya no las come, esos porqués tienes que pensarlos en tu cabeza (A., pescador artesanal, Chipiona, 47 años).
\end{abstract}

Incluso podemos ir más allá, porque la etnografía nos demuestra que quien convive con los animales traslada a estos percepciones humanas en relación con el medio:

Por el mes de mayo, aunque haya mareas
muertas, todavia voy a dar una vueltecita por
la orillita, porque puede haber algún choquito
[choco, Sepia officinalis]. En mayo a los chocos
les gusta mucho la orillita porque les gusta el
fresco [...]. Al choco no le gusta mucho viento,
no le gustan las nubes, como no sean nubes ba-
jas, ésas no le importan. Pero como sean nubes
del sur, de las que traen agua, no, es que se
pierden. No le importa el viento de poniente, si
el agua no sepone turbia no le importa. Ahora,
como se ponga el agua cerrada, ya no entran... (A., mariscador, Chipiona, 48 años).

Esta proximidad con los elementos del entorno y, en particular, con los animales, ha desembocado en formas de pesca simbióticas, ${ }^{10}$ que hoy han desaparecido prácticamente, debido al uso de los equipos tecnológicos. Durante las décadas centrales del siglo $\mathrm{XX}$, se pescaba "al averío", es decir, siguiendo el rastro de aves pescadoras, como las pardelas (familia

10 En distintas conversaciones con pescadores, estos reconocen que siguen con interés los documentales que pueden ver sobre animales, en particular los marinos. Este material se convierte también en fuente de aprendizaje, al incrustar las relaciones que observan en los documentales en las que ellos mismos experimentan en el día a día. De este modo, me recomendaron un documental sobre las técnicas tradicionales de pesca del mújol o lisa (Mugil cephalus) del grupo étnico de los Imraguen, en el espacio natural Banc d'Arguin (Mauritania). Los pescadores se habían ayudado de los delfines, en tanto que predadores, en otro caso de actividad simbiótica. Ver https://www.youtube.com/watch?v=fOTNpM3p-tk en torno al minuto 14. (visitado el 8.02.2017).
Procellariidae), que perseguían bancos superficiales de pequeños pelágicos como los boquerones (Engraulis encrasicolus). A veces, las cadenas simbióticas se ampliaban, incorporando distintos órdenes, el humano y el animal, como ocurría en esas mismas fechas con la pesquería de listados (Katsuwonus pelamis) y bonitos (Sarda sarda) en el Norte de África: barcos de Bermeo (Bizkaia, País Vasco) prestaban sus viveros a los barcos de Barbate (Cádiz), donde se mantenían vivos los boquerones para enguar [cebar] a los túnidos que, una vez concentrados en torno a sus presas, eran rodeados por las traínas (barcos de cerco) andaluces. De este modo, se constituía la pesquería mediante la construcción de relaciones inducidas entre animales y artes de pesca. En sentido similar, los almadraberos hablan de la importancia de las orcas (Orcinus orca) para favorecer la entrada de atunes rojos (Thunnus thynnus) en las almadrabas (Álvarez de Toledo, 2007) ${ }^{11}$ y de cómo los antiguos aprendieron de esta relación el carácter asustadizo y tímido de esta especie para adoptar determinadas técnicas para su captura, tanto en las proximidades como en el interior del arte de pesca, como el uso de atajos y el golpeo de las aguas (Florido, 2017).

Un último apunte de nuestro diario de campo puede reforzar este concepto de comunalidad: uno de los mariscadores de los corrales de Chipiona (Cádiz) recordaba emocionado el saber hacer de una perra de caza que sabía pescar también en los corrales:

Desde chiquitita me la llevaba a la playa. La perra ni se mojaba, tenía una habilidad para llegar a los sitios... Y cogía ella por encima de la pared antes que yo, mirando, y cuando veía un choco [Sepia officinalis] empezaba a ladrar, y cuando iba para el choco ella ya se bajaba y se tiraba al agua. Y ella no cogía el choco mientras no echara tizne [tinta]. Empezaba con las patas a darle hasta cuando echaba tizne, empezaba a buscarlo con las patas y salia

11 Por ejemplo, se ha documentado en el caso de la almadraba de Conil, en la segunda mitad del siglo XVIII, el uso de orcas de madera para favorecer el acercamiento de los atunes rojos (Thunnus thynnus) a la costa, y así poder capturarlos en las almadrabas locales. Esta medida se propuso en un período de crisis pesquera (Álvarez de Toledo, 2007). 
con el choco en la boca y lo dejaba arriba, en la pared del corral. Y al pescado lo atacaba. Pero vamos, las salemas [Sarpa salpa] las cogía muy bien y las ponía encima de las piedras [risas]. Pero el pulpo no lo quería, le daba el bocado y le soltaría una sustancia o algo, que lo soltaba, como el pez sapo [Halobatrachus didactylus] tampoco lo quería. Verás, tenía habilidad de perro... (L., mariscador, Chipiona, 56 años).

Para quien no vive en el lugar, por no conocerlas, esas formas de correspondencia entre predadores (perro, animales del corral y mariscador) y presas (animales del corral), el relato sobre la perra pescadora es atractivo, pero para el analista de estas relaciones lo realmente significativo es cómo el mariscador interpreta el comportamiento del perro: solo captura determinadas especies y ante determinadas circunstancias, convencido como está de la traducibilidad de comportamientos, por responder a un código, el de las relaciones tróficas, que él conoce a través de la experiencia, de los sentidos, de un aprendizaje continuo sobre el terreno. Hablemos entonces de esos entramados relacionales.

\section{Relacionalidad}

Si aplicamos el concepto de 'agenciamiento' de Deleuze y Guattari (2004), la unidad de análisis deben ser las correlaciones entre seres, entre seres y cosas, entre órdenes (el reino natural y el social, el material y el espiritual). Ello implica sustraerse de la sustancialidad, de la esencialidad de cada objeto, de cada orden, incluso de cada yo. La subjetividad es aquí un haz de conexiones, entre cada yo y cada otro, incluyendo dentro de este otro los objetos, los animales, y cualquier elemento que se considere significativo. Lo importante no es la individualidad, sino cómo el saber heredado entra en conexión y es afectado por, al mismo tiempo que afecta a, el resto de cosas del mundo con contagios que no siempre son buscados, sino que el pescador debe saber leer a partir de las inscripciones en su hacer cotidiano. La imagen apropiada remite a un ensamblaje en red, una "multiplicidad rizomática" basada en múltiples cofuncionamientos. Se trata de concebir la realidad "como proceso de producción, como apertura y devenir" (Heredia, 2014, p. 94).
Aquí partimos de la hipótesis de que esta estructura es ontológica, además de discursiva, y que el sujeto pensante tiene un papel destacado en su configuración, pero que no agota la producción permanente de conexiones entre sujetos y objetos de distinto orden -a diferencia de lecturas más radicales, que aceptan una simetría entre el actor y el resto de actantes en la configuración de esa red-. Por tanto, los relatos y las prácticas de los pescadores construyen la íntima conexión entre todos los elementos, vivos y no vivos, humanos y no humanos, que constituyen las 'culturalezas' locales marinas. Estas relaciones socioecosistémicas son explicadas en distintos niveles: relaciones tróficas entre las especies (los pequeños pelágicos son tenidos como el "pasto" del mar); los impactos de las técnicas de pesca y de otros elementos resultado de la ingeniería humana sobre las poblaciones animales y vegetales; o en correlaciones observadas entre distintos comportamientos animales. Veamos:

i) Puesto que un corral es un espacio intermareal acotado mediante piedras, los mariscadores que los mantienen y trabajan tienen un conocimiento de los comportamientos de los animales.
Las doradas (Sparus aurata) levantan las pie- dras pequeñas y luego se comen los cangrejos. $Y$ luego, a las almejas las sopla y abren un aguje- ro. - ¿Las soplan? - Si, las soplan en la cascajera [arena de grano grueso mezclada con restos de conchas] y abren un agujero hasta que dan con la almeja, pegan un bocadito y te dejan cuatro cascaritas (L., mariscador, Chipiona, 56 años).

Para poder tejer un discurso que sea capaz de representar estas relaciones en el ecosistema, el mariscador debe hilar distintos indicios: la copresencia de especies, la comprobación de los buches de los predadores, los restos de los ejemplares aniquilados, la "cama" o huella que dejan algunas especies que se entierran en el lecho, además de la verificación directa de acciones de caza entre predadores y presas.

ii) Al explicar el impacto de unos sistemas de pesca sobre las poblaciones objeto de cada flota, los pescadores dan cuenta de redes conectivas: la intensificación para capturar chirlas (Chamelea gallina) en 
las playas del Espacio Natural de Doñana (CádizHuelva) mediante dragas hidráulicas -que emiten un potente chorro de agua sobre el sustrato para descubrir a los bivalvos enterrados- afecta las ovas de las especies que aquellos quieren pescar (pescados de roca), afectando la ecología de los suelos y, por tanto, la dinámica ecosistémica de la Reserva de Pesca de la desembocadura del Guadalquivir. "Una cosa va en relación con la otra", nos dice un pescador artesanal, que se siente amenazado por la acción no controlada de esos barcos más tecnificados. De este modo, los pescadores de Chipiona y Sanlúcar (Cádiz) reclaman a los investigadores del Instituto Espańol de Oceanografía que estudien estas conectividades y compartan los resultados. ${ }^{12} \mathrm{Si}$ bien muchas veces los razonamientos en este sentido se interpretan como una mera estrategia territorial de los afectados (Sánchez-Fernández, 1992), lo cierto es que muestran hasta qué punto el pescador tiene conocimiento de las conexiones entre todos los elementos del socioecosistema, incluyendo los equipos de pesca y las medidas de gestión y de investigación científicas. No son métodos tecnocientíficos los que ellos usan para mostrar estas correlaciones, sino su experiencia: el descenso del tamaño medio de las capturas, el descenso de la biomasa capturada, o la constatación de que la presión pesquera y la contaminación marina están induciendo el adelantamiento de la edad de madurez sexual de algunas especies: bailas (Dicentrarchus punctatus), galeras (Squila mantis), cangrejos (Carcinus sp.), en el estuario del Guadalquivir. "La naturaleza es sabia y dice: 'esto qué es?', y adelanta la edad de poner huevos. Eso es lo que deben investigar los cientificos", nos explica un mariscador de Chipiona. "Tenemos la muestra de que nosotros antes ibamos ahi a coger las bailas [Dicentrarchus punctatus], que pesaban un kilo, un kilo y medio, tres cuartos de kilo, y hoy vas tú, y no las coges".

Las redes tróficas son tenidas en cuenta para definir estrategias de pesca, que imitan las relaciones predador-presa: al llegar a las piedras donde se cobijan determinadas especies, robalos (Dicentrarchus la-

12 Manifestaciones obtenidas en el Grupo de Trabajo entre pescadores, técnicos de la administración y científicos que tuvo lugar en Chipiona (Cádiz) en junio de 2016. brax), corvinatas (Umbrina cirrosa o Sciaena umbra), los aparejos han de colocarse teniendo en cuenta el sentido de la corriente dominante, tal y como lo hacen las especies predadoras para alimentarse, evidenciando así la continuidad y traducibilidad de las prácticas humanas y animales. "Lo mismo que ellos saben ponerse en relación a la corriente para coger sus presas, asi nos colocamos nosotros para cogerlos a ellos" (P., pescador artesanal, Barbate, 57 años). En otras ocasiones, se usan los indicios de las relaciones tróficas entre especies, como ocurre con el pulpo, gran depredador, en los corrales:

Claro, tú pasas y ves las cáscaras de almeja, ves las cáscaras de muergo [Ensis minor], ves las cortezas de los cangrejos,... hay un pulpo [Octopus vulgaris] [risas]. Es que, aunque es muy inteligente, tiene esa enfermedad de llevarse la basura a su casa, ¿comprendes? Eso no es bueno para él, para ti sí, si sabes mirar, enseguida lo ves (L., mariscador, Chipiona, 56 años).

Y del mismo modo, en zonas frecuentadas, los pescadores reconocen intuir la presencia de presas habituales, si se dan determinadas condiciones: temperatura del agua, corrientes y otros atributos hidrodinámicos, "...porque los animales van buscando su..., tienen como su sitio". Y pueden llegar a interpretar los comportamientos territoriales asociados, por ejemplo, al apareamiento:

\section{Porque el choco [Sepia officinalis] tiene una cosa, que mucha gente no se ha fijado, yo me he fijado, el macho entra antes, a buscar un terri- torio, y según el territorio que tenga el macho asi tiene la hembra. El macho entra y se coge su territorio donde hay más comida, donde está más a gusto, donde está más aguardadito [sic]. Ahora entran las hembras, y la hembra se va a ir con el macho que tenga mejor casa. Como las mujeres [risas], no se va a ir con el que tiene una choza [...]. Y digo, pues hoy he cogido ma- chos, mañana cojo hembras (L., mariscador, Chipiona, 56 años).}

En ocasiones, esta experiencia acumulada les permite intuir algunas conexiones que contradicen 
los postulados de medidas conservacionistas, como el fondeo de arrecifes artificiales para crear microhábitats de refugio de alevinaje (los denominados "módulos productivos") en la Reserva de Pesca de la desembocadura del Guadalquivir (ChipionaSanlúcar, Cádiz). Así, algunos pescadores artesanales (Punta Umbría -Huelva- o Chipiona) han indicado que estos nuevos espacios atraen predadores de otras zonas, que se alimentan de las crías de las especies que son objeto de pesca de los marineros locales, por lo que demandan análisis científicos en este campo al sospechar que tales módulos producen dinámicas no esperadas que les afectan negativamente.

iii) Pero el principio de relacionalidad amplía su rango de extensión, sobrevuela el entorno marítimo y las especies marinas y alcanza otros territorios y "biosferas" próximas. Así, uno de los informantes (Chipiona, Cádiz) reflexiona sobre la conexión existente entre el comportamiento migratorio de peces y aves: flamencos (Phoenicopterus), patos, ánsares (Anser anser)... "Nosotros pensamos, yo pienso que esos animales siempre vienen a su hábitat de nacimiento, de apareamiento, lo mismo que las clases de pescado". Así queda explicado en el caso de las doradas (Sparus aurata) en los corrales:

Nacen las chiquititas, ya las hay asi chicas de este año, de las que han nacido este verano pasado, las hay con media cuartita, una cuartita... dentro del corral, que cuando las alumbras hacen, jzzz! $Y$ se entierran [risas]. Ahora, cuando ellas creen que ya tienen un tamaño que las pueden coger, se largan y ya no se quedan por aqui, se van y vuelven cuando son mayores, adultas, vuelven otra vez, ya a ovar. Es como los pájaros o las golondrinas [Hirundo rustica], me supongo yo, que ellos se van $y$ vuelven (L., mariscador, Chipiona, 56 ańos).

Otras veces, incluso, las correlaciones llegan a animales extraños al hábitat local, como en el caso narrado por un pescador artesanal de Chipiona, en el que una tortuga doméstica, cuando despertaba de su hibernación, era utilizada como indicador biológico para saber que daba inicio la pesquería del langostino (Penaeus kerathurus). El descubrimiento fue de su mujer y casual, pero desde ese momento lo apuntó en su libreta: "Oye, sea más tardío, o sea más adelantado, porque nunca eran exactos los días, pero cuando despertaba Coral [la tortuga], según el animal salía, en esas fechas empezábamos a coger el langostino" (J., pescador artesanal, Chipiona, 55 años).

Las manifestaciones de esta visión relacional, cuando aplicamos una perspectiva histórica, antes de la proliferación de los dispositivos tecnológicos, son múltiples. Los pescadores habían de interpretar determinados indicios del entorno para identificar territorios y momentos de pesca, así como para presumir cambios de tiempo atmosférico. Entre dos pescadores que conversaban sobre sus conocimientos en las labores de pesca, uno pedía a su compañero confirmación de que el choco (Sepia officinalis) es el animal que más claramente marca la mudanza de tiempo, cambiando su cuerpo de color y semejando "sacar unas puyas [púas]", por lo que es "la especie más marinera que hay". Uno de estos informantes nos relataba qué le enseñaba un viejo marinero con el que empezó a pescar, en los años setenta, en relación a la presencia y comportamientos de los charranes o paínos (Sterna hirundo), aves que entendía como indicadores de inminencia de variaciones atmosféricas:

Cuando veia las golondrinas de mar, tú estabas faenando $y$, de buenas a primeras, empezabas a ver paiñitos de esos por la popa del barco. $Y$ te decia: "Hoy no calamos", y estaba la mar calma. Y tú decías: “Y esto por qué?". "No, mira los paiños, ¿ves los paiños lo que están haciendo, por encima del agua y esto? Mañana tenemos ventazo".

Sobre este aprendizaje, él pudo sumar otros del mismo tipo:

Cuando tú ves a los albures [Mugil cephalus] saltar en la mar, tú te quedas mirando hacia dónde ponen la cara cuando saltan, y si te das cuenta ese día todos saltan con la cara hacia el mismo lado, y es porque al día siguiente el viento va a venir de ahi; es decir, ellos saltan cara al viento, adonde va a entrar viento (A., pescador artesanal, Chipiona, 47 años). 


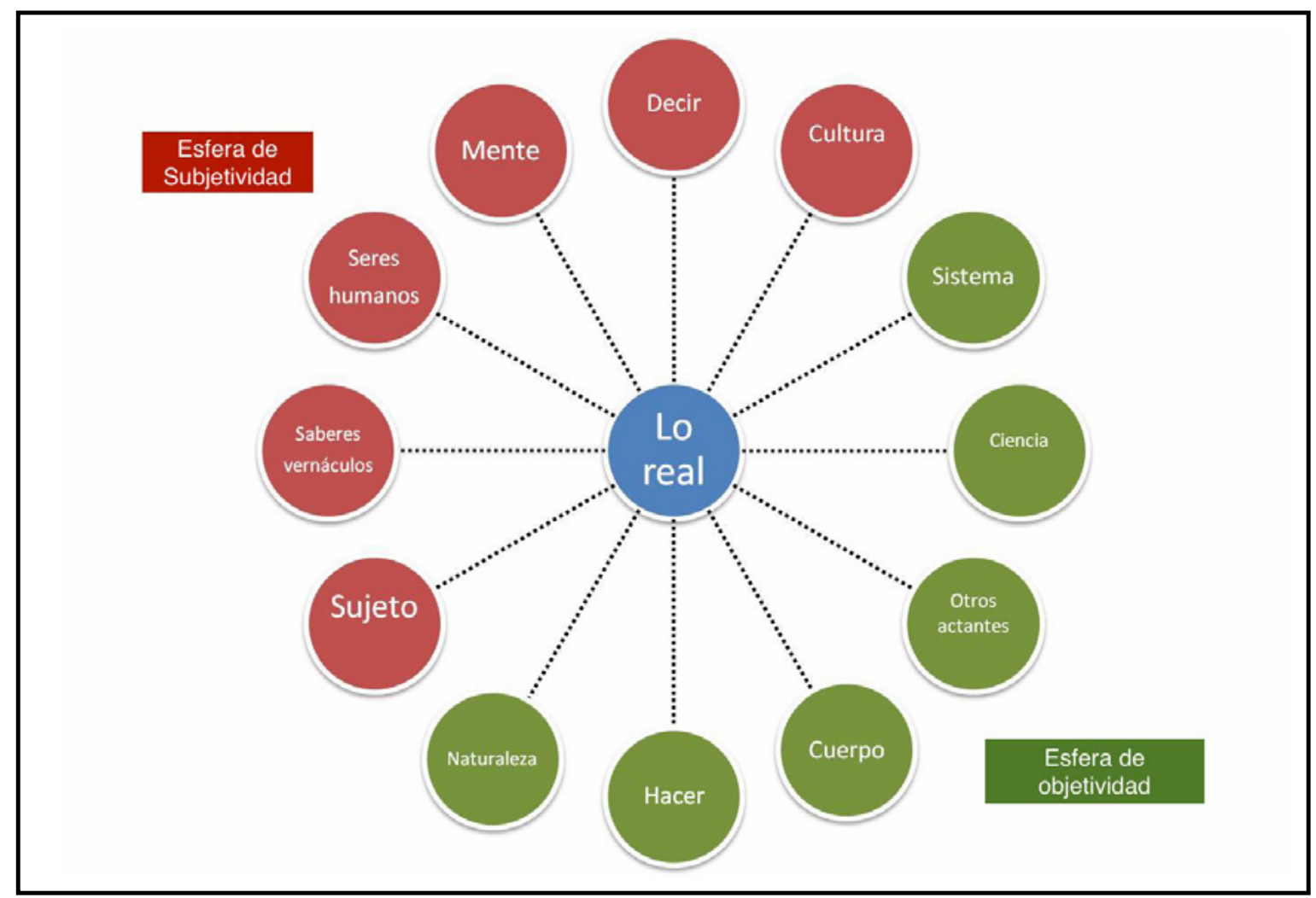

Figura 3. Hibridaciones y relaciones en la etnografía desde el giro ontológico. Fuente: Elaboración propia.

Del mismo modo, testimonios sobre la relación entre el color de los destellos solares del ocaso sobre las aguas son frecuentes, tanto para presagiar tiempos de calma como para barruntar jornadas de vientos intensos (cada uno con sus matices), o la relación entre la fuerza de la corriente, en ausencia de viento, y la previsión de vientos locales con fuerza en una determinada dirección. Hoy ya, nos confiesa este informante, los jóvenes miran "el parte" (previsión meteorológica), pero si sigues usando aquellos indicios, es decir, los que usaban los pescadores experimentados, puedes constatar que "son reales".

En definitiva, cualquier relato etnográfico muestra un indudable dominio de las conexiones entre elementos bióticos (redes tróficas entre animales, comportamiento sexual, prácticas territoriales), abióticos (factores atmosféricos y oceanográficos: vientos, corrientes, luna, etc.) y equipos de pesca (Florido y Maya-Jariego, 2018). El concepto-fenómeno -cuasi herramienta cognitiva y de investigación (subjetiva), cuasi práctica de apropiación material (objetiva)- que logra vincular esta red de relaciones es el de "arte de pesca", que requiere de un conocimiento enactado, de un saber hacer práctico, en el que el pescador es un nodo, privilegiado, del sistema, que sirve para trabar las conexiones íntimas entre los modelos de comunalidad y la relacionalidad expuestos.

Lo llamativo es que este proceso está siempre abierto, discurre mediante alteración-desestabilizacióninnovación de lo real de modo constante: tiene su "cuota de infinito", según Heredia (2014). Establece sendas, al mismo que guías para abrir otras nuevas, reconfiguraciones..., de ahí la pertinencia de la metáfora del rizoma (Deleuze y Guattari, 2004). Es un proceso de estabilización en situación de inestabilidad, pudiendo superar así las rigideces a las que sometemos el pensamiento y lo real mediante las dicotomías habla-lengua, intención-contexto, actorsistema, acontecimiento-estructura... (Figura 3). La metáfora del espacio liso de Deleuze y Guattari (2004), aplicada al modelo marítimo, nos esclarece su socio-naturaleza. En ese espacio marino cultivado 
por el pescador, de carácter preastronómico, ${ }^{13}$ se trabaja con conocimientos nómadas, caracterizados antes por líneas y vectores que por puntos y posiciones; antes por acontecimientos, síntomas y experiencias (Florido, 2002) que por mediciones. Las referencias cognitivas que usan los pescadores -aquellas "cartas hidrográficas mentales" de Sánez Reguart- son de este orden: corrientes, vientos, suelos, sonidos, olores, comportamientos de los animales, que navegan por el mar y por el aire. Cierto es que la incorporación de las nuevas tecnologías está colaborando a estriar el espacio: a establecer puntos, extensiones, medidas precisas, de modo que la experiencia espacial se va haciendo más y más heterogénea, como pretendo mostrar en el siguiente apartado.

\section{Los dispositivos tecnológicos}

¿Y de qué modo se conectan los nuevos dispositivos tecnológicos con las redes representadas y enactadas por los pescadores? Cuando he preguntado sobre la imbricación de conocimientos tradicionales y dispositivos tecnológicos-por ejemplo, a propósito de los sistemas de marcas visuales para posicionarse en el mar, o a propósito de la rica información que sobre fondos y cardúmenes ofrecen hoy las pantallas de las sondas- los pescadores de pequeña escala son reacios a reconocer el importante papel de los nuevos dispositivos, pues el saber hacer no tiene solo una vertiente funcional o instrumental: genera sentido social e identidad, de modo que la presencia de los aparatos se entiende como una práctica desprofesionalizante.

Para evitar cualquier forma de idealismo, "la teoría debe vincular sistemáticamente la conducta con la interpretación; debe ser una teoría de la conducta"

13 Nos referimos a la dicotomía "liso-estriado" aplicada al medio marino. La navegación de altura se fue desarrollando mediante la instauración de un espacio estriado, construido sobre la marcación de puntos en el espacio marítimo como consecuencia de la sobreimposición de líneas, una vez que el Estado impulsó el dominio territorial, aunque parcial, de los mares. Esa demarcación de puntos fue resultado de la sobreimposición de cuerpos celestes, no obstante. Por su parte, la navegación de zonas litorales (modelo de espacio liso según Deleuze-Guattari, 2004) siguió su curso a partir de las referencias experimentales de navegantes de cabotaje, marineros y pescadores.
(Douglas, 2008, p. 143), por lo que hemos de comprobar de qué modo las representaciones, asimilaciones, metáforas y percepciones humano-ambientales de los informantes se enmarcan en prácticas, son efectivamente enactadas y el uso de equipos tecnológicos para la pesca es especialmente adecuado para esto (Figura 4). Así, al acompañarlos en sus salidas de pesca, aprecias con nitidez que los pescadores ya han "incorporado" dentro de su red cognitiva estos dispositivos. "Pescar al aparato" (Florido, 2002) ${ }^{14}$ es una de las modalidades básicas de la pesca al cerco en la actualidad para pequeños pelágicos. Los patrones han aprendido a adivinar por las formas y densidad de las manchas de pescado de la pantalla de la sonda de qué especie se trata (Figura 5). Del mismo modo, van almacenando información sobre la relación entre tipo de suelo, salinidad, temperatura del agua y territorialidad de las poblaciones que van buscando. Gracias a los sistemas de posicionamiento geolocalizados (plotter, AIS), los patrones controlan su posición y la de los demás, alterando prácticas tradicionales sobre distribución de la información, especialmente en las pesquerías más tecnológicas. El siguiente testimonio de un patrón de un barco de arrastre es suficientemente elocuente y muestra meridianamente el sentido de conocimiento incorporado y enactado:

Si, el aparejo te habla. Conforme va entrando por la popa del barco, te va dando el roce de las puertas sobre el fondo y te va a decir qué tipo de fondo es. $Y$ después la propia malleta, que es la antesala del arte, le pasas la mano, $y$ te va soltando como un agüilla, esa agüilla te va diciendo también, te va comentando si es un fondo blando, incluso en el mismo fondo, en distinto tiempo vas a tener el fondo más blando o menos blando. Son todos indicadores que tienes que ir aprendiendo con el tiempo, a bordo. Es un lenguaje que tú en ese momento ves y tú mismo procesas, pero no transmites. Los aparatos nos han dejado sin territorio de pesca, pero te refugias en este lenguaje. El que lo quiera aprender sólo lo puede hacer viéndote (S., pescador de arrastre, 40 años).

14 En contraste con otros términos que hasta mediados de siglo eran habituales para definir sistemas de pesca, términos que recreaban los sentidos corporales, como "pescar a la vista", "al arda”, "a la escucha” (Florido, 2002). 


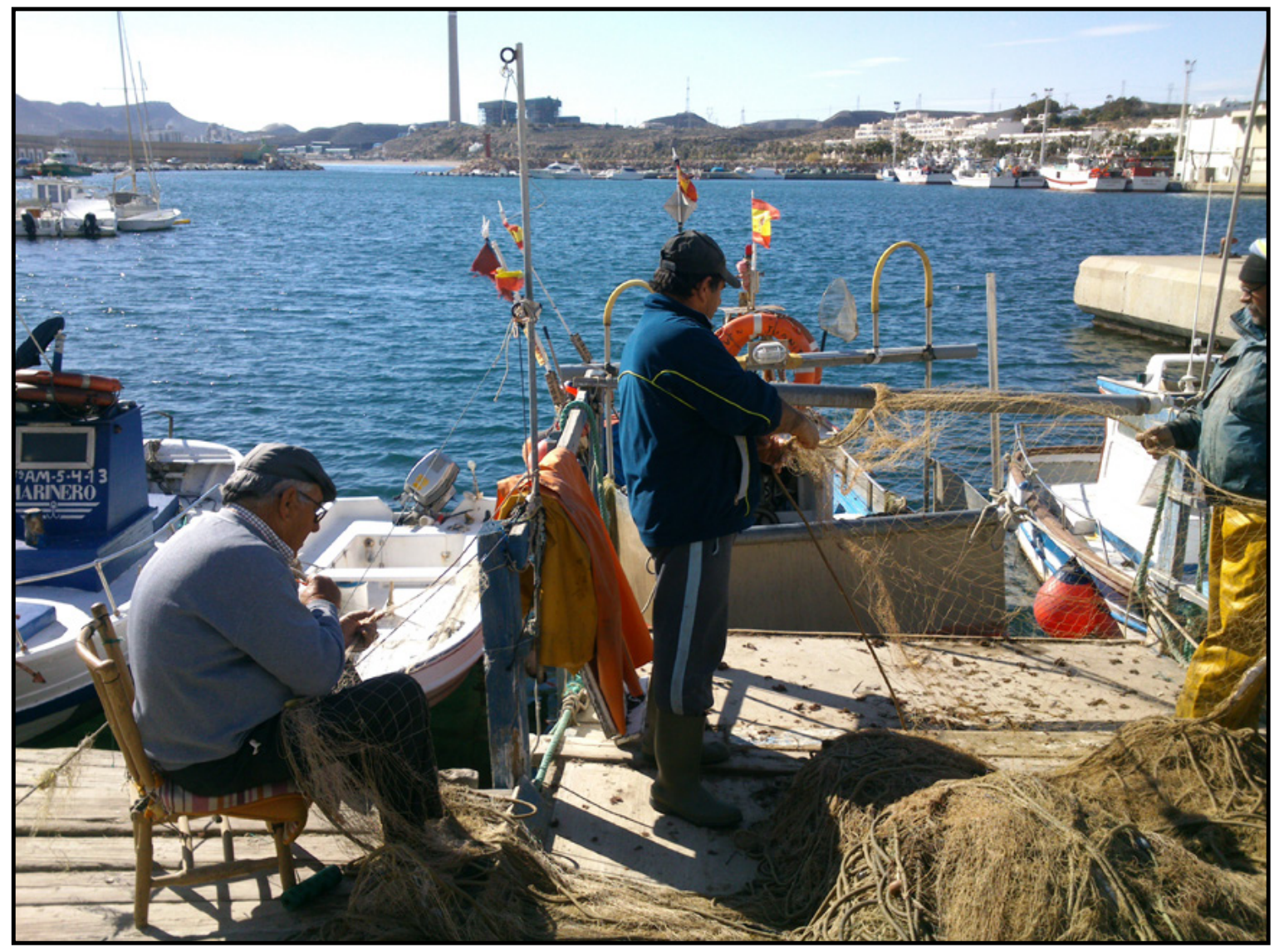

Figura 4. Pescadores repasando el trasmallo. Carboneras (Almería). Mientras revisan los pańos, el marino va leyendo, con sus manos, cualquier indicio prendido en la red para producir conocimiento sobre el territorio y la pesquería. Fuente: Autor.

Como se reconoce en la teoría del actor-red, en lugar de sujetos y objetos, nos enfrentamos a actantes (personas, entidades, dispositivos, entes no humanos...) constituidos por redes que se despliegan en un proceso semiótico que acompaña las relaciones entre hombres-poblaciones-entorno-equipos de pesca. Ninguno de los polos (las condiciones ambientales, los equipos tecnológicos, la intención del pescador) existe como factor explicativo separable, sino como "explanandvm", como una (micro) totalidad en constante modo de generación (Law y Mol, 1995). Individuos, instituciones, dispositivos se van configurando mediante multitud de ensamblajes y traducciones (Latour, 1992; Callon, 1995). Los entes que sostienen y son sostenidos por las redes son cuasi-sujetos-cuasi-objetos, de modo que podríamos imaginarlos como un momento o una trayectoria que definimos en el instante en que la convertimos, ellos mediante su conocimiento enactado, nosotros mediante nuestro discurso (científico), en lo real (ver Figura 3). Ese mismo pescador de arrastre explicaba que el agente comercial encargado de vender las sondas

\section{[...] me ofrecía los parámetros de barcos de otros puertos, que pescaban mucho, y yo de esos pará- metros aprendia una barbaridad, con esos pará- metros sobre la velocidad, la abertura de puertas y la altura del arte, ya sabia yo la especie a la que iba, no me hacia falta ni profundidad ni nada. El buen patrón aprende indagando sobre los parámetros, y si tiene información de otros buenos barcos, pues...}

Así, cuando queremos aplicar el modelo de actorred al caso de estudio, tendremos que reflexionar sobre los dispositivos cognitivos (un saber-hacer) que 


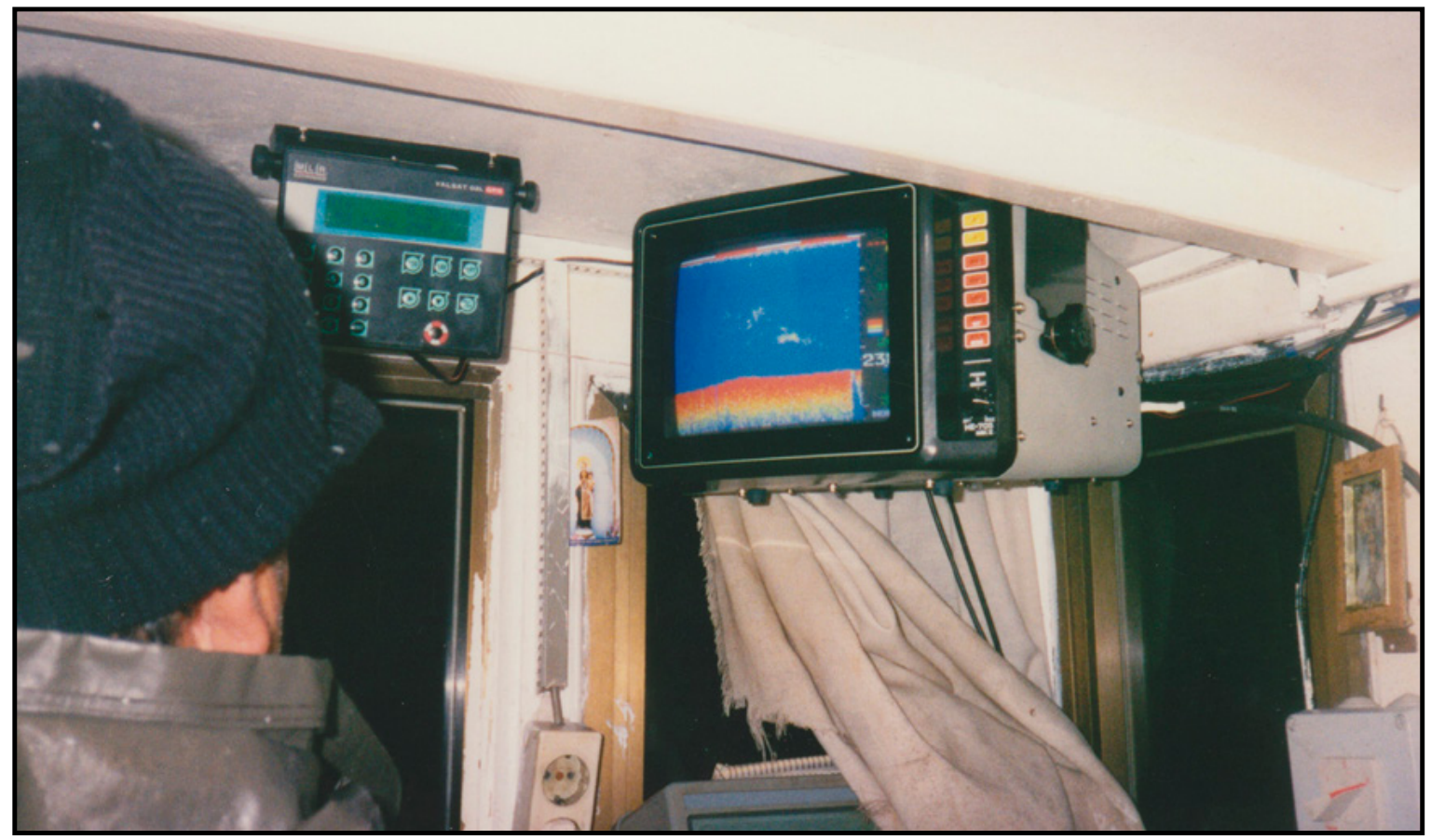

Figura 5. El puente de un cerquero en Barbate (Cádiz). El puente es el lugar donde el patrón se inscribe en relaciones que constituyen su modo de apropiarse del medio marino. Aquí lee las formas de las "manchas" en la sonda de "color" para interpretar qué especies están siendo detectadas y decidir si echar el lance o no. Fuente: Autor.

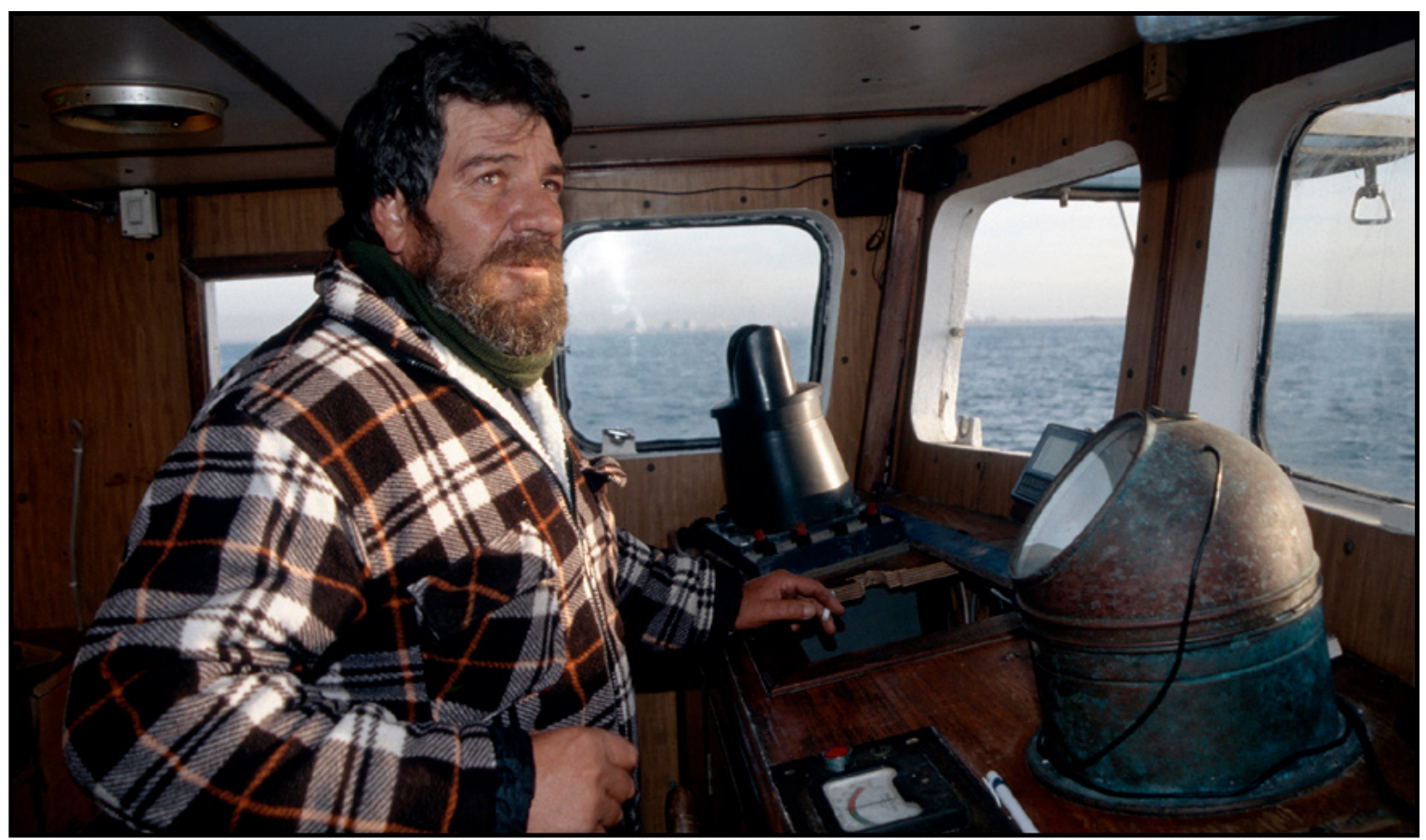

Figura 6. Puente de un barco artesanal en El Rompiso (Huelva). Experiencia, memoria, sondas, dispositivos de posicionamiento, cuadernos, plotter..., todos son artefactos epistémicos mediante los que se produce el conocimiento enactado. Fuente: Juan Ruiz (IES Rafael Cartaya). 
se instituyen en contextos de interacción a escala micro, como el puente de un barco (Figuras 5 y 6 ). Sin embargo, para tener el marco completo hay que considerar un contexto más amplio. ¿Cómo es posible constituir así un acervo, entendido como un depósito, en el marco de una colectividad social? Son las asociaciones específicas, las conexiones íntimas entre personas y sus conocimientos compactados en recuerdos los que permiten procesos de enactación cuando el pescador ha de interpretar el abigarrado cuadro de datos que tiene a su alcance para tomar una decisión. Nos decía un pescador de pequeña escala:

\section{Yo iba de joven con un señor para que me en- señara las marcas de tierra [posicionamien- to de pesqueros con referencias visuales en tierra], pero al llegar al sitio, me decía: "Aqui es la piedra: pero coge tú tus marcas, porque tienes que coger las tuyas propias". Y al final lo entendi: tú tienes que buscar las que puedas recordar, las que puedas controlar tú, que al- gunas son conocidas por todos, pero otras son de cada quien (F., pescador artesanal, Chipiona, 55 años).}

Los testimonios que manifiestan esta continuidad de saberes se caracterizan por reconocer una herencia, que se ha ido consolidando en el tiempo, y que tiene un ineludible carácter social, como reconoce Descola (2011, p. 86), pero que necesitan su enacción en cada momento concreto, volviéndose el pescador y sus artefactos nodos en el proceso de conocimiento, momentáneamente claves para la reproducción social: de los saberes y las prácticas, las actividades de pesca y el entramado social que le sirve de marco.

Los signos proceden del mundo animal, del medio físico, del resto de actores y de los artefactos, y solo en la acción, mediante su cerebro (incluyendo proceso cognitivo reflexivo, intuiciones, sensaciones, experiencia acumulada) y su cuerpo, y las extensiones de este -los artefactos epistémicos de Dennet (1996)-, ${ }^{15}$ solo de este modo, ese conocimiento se

15 Objetos construidos por el hombre para facilitar el almacenamiento y procesamiento de la información, liberando así al cerebro en sus tareas cognitivas y expandiéndolo en el entorno. Bueno es recordar que algunos de estos hace real (ver Figura 3). Si en un tiempo era el cuerpo del pescador uno de sus principales artefactos, pues le servía de patrón de medida para ubicarse en el territorio y era el instrumento clave mediante el que fabricaba sus artes y llevaba a cabo sus acciones de pesca (Sáńez Reguart, 1791), ${ }^{16}$ hoy sus capacidades se extienden y distribuyen, además y sobre todo, entre los artefactos técnicos (Figuras 7 y 8). De este modo, la articulación entre elementos del entorno, el acervo de conocimiento y los artefactos técnicos se interconectan de un modo crecientemente heterogéneo mediante el conocimiento enactado del pescador. Antes y ahora los cuadernos y libretas de los capitanes de almadraba y de los patrones de pesca han servido como artefacto epistémico mediante el cual se amplía la maquinaria cognitiva.

Eso lo he vivido yo, que coge uno experiencia
con los pescados que se queda uno... Coinci-
diendo con las mareas, coincidiendo con esto,
en tal sitio, en tal fecha, en tal año..., porque yo
tenía mi diario donde apuntaba todos mis tra-
bajos: día tal, en tal sitio, en tal hora, hicimos
esta pesca..., y todas esas cosas, tú las buscabas
al año siguiente en esos mismos sitios, por esas
mismas fechas y estaban. Por eso digo yo que
el pescado te dice: "sí, esto lo hago yo también
aqui" (A., patrón de pesca y mecánico naval
jubilado, Barbate, 73 años).

Estamos, por tanto, ante procesos de cognición híbrida, de carácter extendido (Vega, 2005), ${ }^{17}$ en los

artefactos posibilitan, pero también limitan, al "mediar" las capacidades del sujeto.

16 No me resisto a traer aquí esta bella cita: "Los pescadores tienen en sí mismos quantas medidas necesitan para verificar los cálculos relativos á su extenso exercicio. Con ellas reconocen exâctamente toda la variedad y continua desigualdad de los fondos del mar (...) Ellos son por otra parte unos excelentes Naturalistas casi por naturaleza, y sin nociones algunas de otra escuela y estudio que de su mismo exercicio (...) La experiencia nunca desdice de aquella ciencia verdadera y sólida, que adquirieron natural y prácticamente, para aprovechar las utilidades correspondientes á su profesión y su trabajo” (Sáńez Reguart, 1791, vol. II, p. 294).

17 "Por cognición extendida se entiende el conjunto de programas en el estudio de los procesos cognitivos en los que se admiten aspectos del entorno de un organismo como parte del sistema de procesamiento cognitivo" (Vega, 2005, p. 3). 


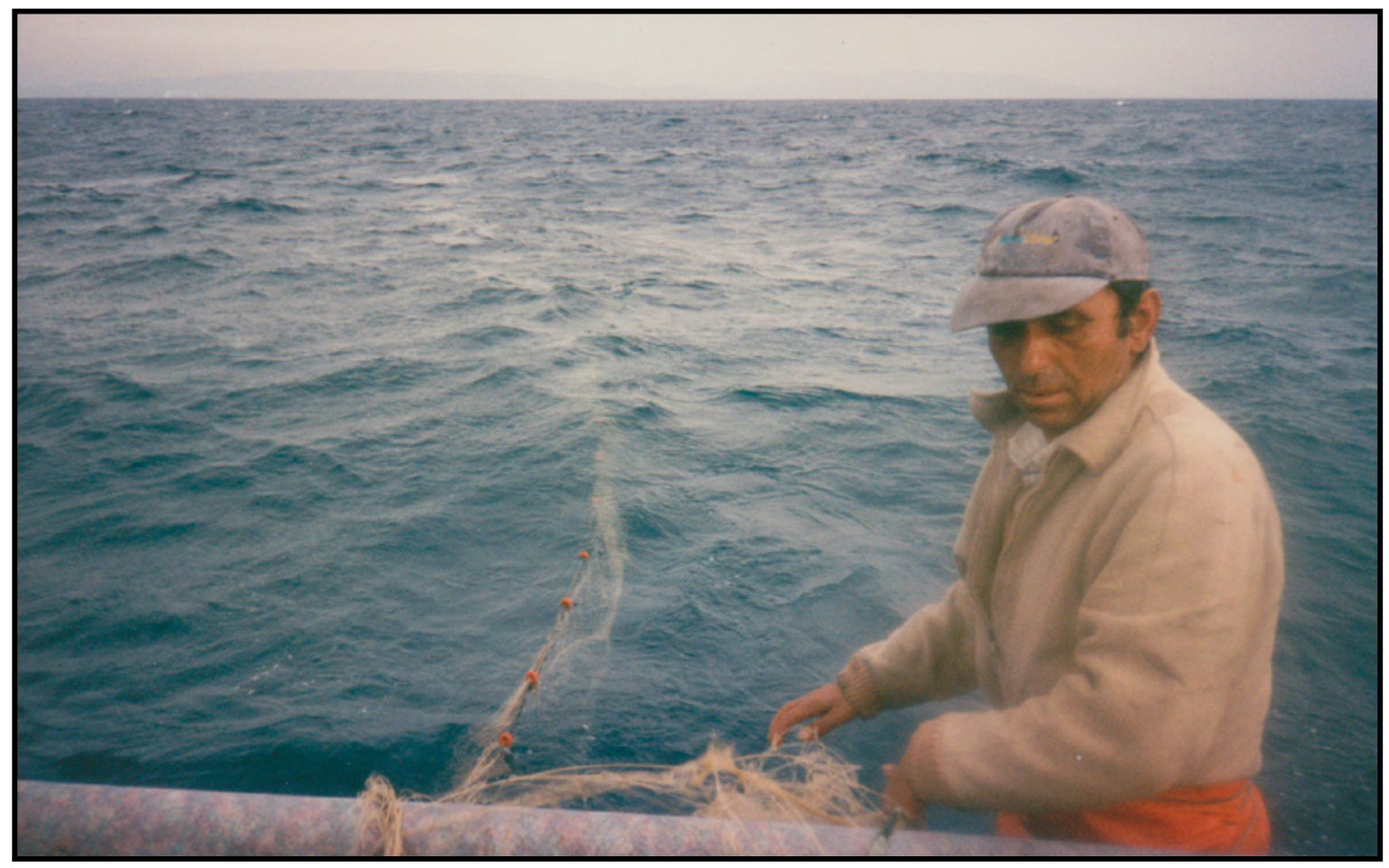

Figura 7. Marinero de trasmallo largando el arte en las costas de Barbate (Cádiz).

"La mar no es infinita, como el horizonte, sino que nosotros pescamos en determinadas zonas". Fuente: Autor.

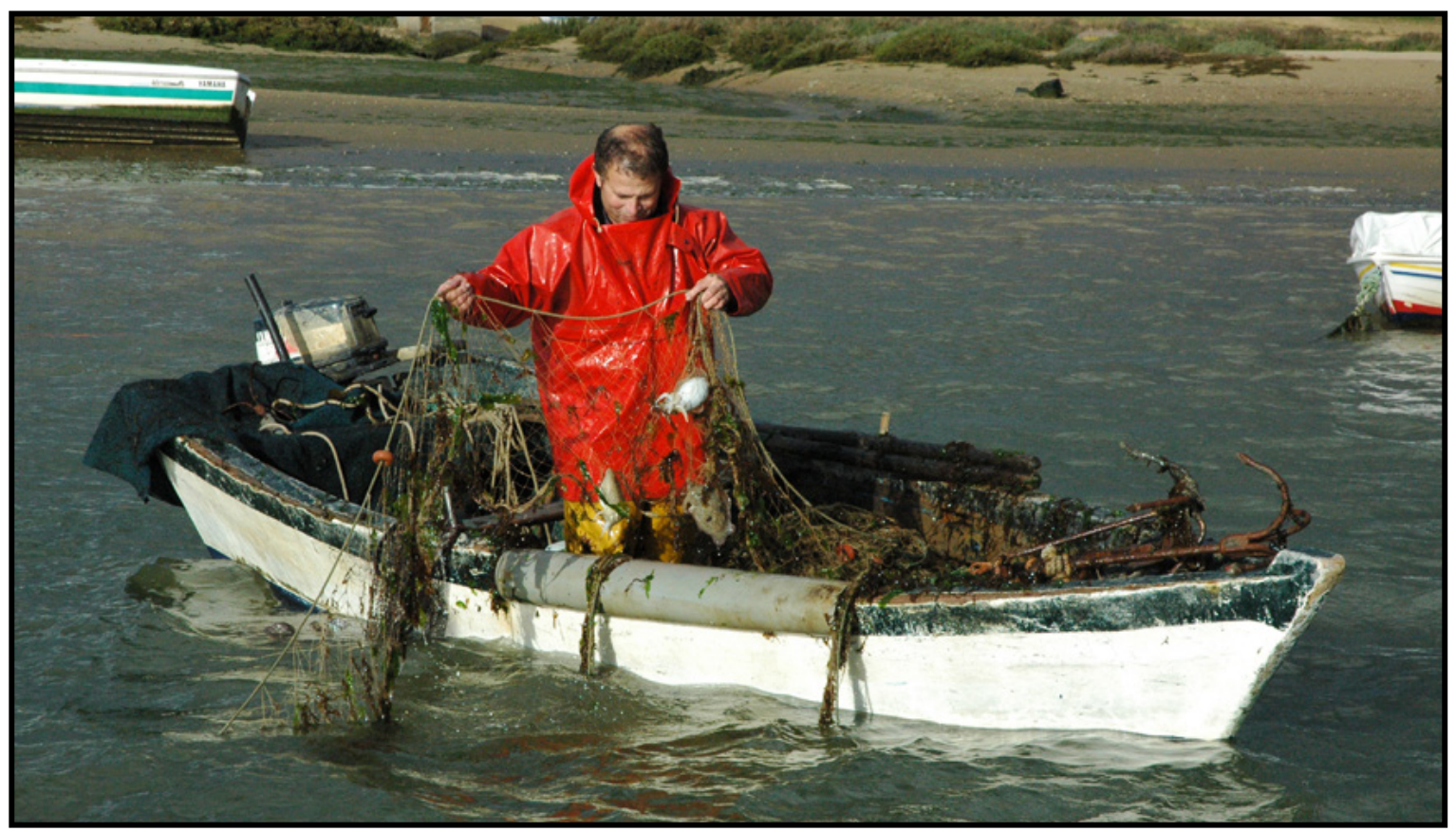

Figura 8. Pescador recogiendo el trasmallo en las costas de El Rompido (Huelva). La red ya no es un mero instrumento del quehacer del pescador - un instrumento que ha sido producto de un saber-hacer constituido sobre todas esas interconexiones-, sino la metáfora que mejor representa su ontología. Fuente: Juan Ruiz (IES Cartaya). 
que el proceso de conocimiento implica distintas relaciones, humanas y no humanas, internas al sujeto y externas (Tirado y Doménech, 2005). Frente al modelo internalista clásico de conocimiento, de inspiración cartesiana (la mente como locus ontológico, independiente del cuerpo y del entorno, con una subjetividad intencional nítida y que se representa el mundo objetivo pre dado), nos encontramos con la propuesta del conocimiento enactivo, corporeizado o encarnado, ${ }^{18}$ situado, en el que ser-saber-hacer se entienden indisociables (Maturana y Varela, 1987). Aquí las representaciones están antes distribuidas que localizadas. Desde este enfoque, los sujetos están incrustados en contextos que son clave para la constitución de los procesos cognitivos. Sujeto y mundo se configuran recíprocamente, relacional y comunitariamente, pudiendo así eludir la dicotomía entre idealismo subjetivista y realismo objetivista. Es la permanente conexión con el mundo la que hace surgir el conocimiento en cada situación, permitiendo la constitución de conocimiento organizado desde la experiencia corporal (Clark, 1999), de modo que la mente es resultado de la conexión cuerpo-entorno.

\section{¿Sostienen una ontología los pescadores? hacia un encuentro de racionalidades y saberes}

Llegados a este punto, vale la pena preguntarnos si los pescadores, en sus distintas modalidades, logran sostener una ontología, al modo como la define Descola: esquemas de percepción de la naturaleza que les permiten pensar, clasificar el mundo y relacionarse con él; "sistemas de propiedades de lo existente que sirven de punto de anclaje de las formas cosmológicas, de los modelos de lazo social y de las teorías de la alteridad" (Descola, 2011, p. 87). Nos enfrentamos a un colectivo social que se caracteriza por una acusada diversidad de prácticas,

18 Las cualidades de la cognición, desde esta perspectiva serían, siguiendo a Vega: corporeización del conocimiento, importancia de la imaginación, construcción cognitiva en la práctica -en contextos situacionales que exigen respuestas flexibles-, conocimiento enactivo expresado en prácticas que relacionan al sujeto con el mundo, que es resultado de ese proceso y no preexistente a él. en función de variables socioeconómicas (Florido, 2008). ${ }^{19}$ Además, hemos de tener en cuenta que entre los pescadores contemporáneos de sociedades industrializadas se constata claramente una intencionalidad predatoria relacionada con el economicismo imperante y resultado de los esquemas cognitivos de naturaleza que lo acompañan, que la objetifican y la reducen a recurso. Desde luego, no son trasladables sin más las ontologías que evidencian una continuidad social-natural, como el animismo, el totemismo o el analogismo (Descola, 2011, p. 87 y ss.). A diferencia de los referentes sociales de estas ontologías (sociedades totémicas australianas, comunidades indígenas de América, imaginarios europeos premodernos), estos modos perceptivos no se traducen, en el caso de los pescadores, en un esquema que ordena las relaciones sociales y el resto de aspectos de sus cosmovisiones de modo holista. Sin embargo, en el específico, y crucial, ámbito de las relaciones humano-ambientales que contienen una actividad de apropiación, material y cognitiva, del medio marino, sí subsisten rasgos solidarios con el modelo comunalista, según he querido evidenciar.

Para argumentar este extremo, he querido explicar que el pescador actúa y piensa desde dentro de una red de interconexiones. Sus mecanismos de conocimiento están efectivamente distribuidos entre dispositivos (los equipos y artes de pesca) y su propio cuerpo; entre su mente y sus elementos biológicos (sus manos, sus ojos - parafraseando a Latour, piensan con las manos, con la vista, con el oído, además de con el cerebro-); entre ellos mismos y sus antecesores; entre su posición como seres humanos y los mensajes que deben decodificar de las redes tróficas de seres vivos, de elementos atmosféricos, de patrones de territorialidad animales y humanos, porque los otros pescadores también cuentan, y porque cada vez más han de tomar decisiones teniendo en cuenta las redes económicas en las que están insertos. La red ya no es un mero instrumento de su quehacer -un instrumento que ha sido producto de un saberhacer constituido sobre todas esas interconexiones-, sino la metáfora que mejor representa su ontología.

19 No estamos en condiciones de hacer una cartografía de los sistemas de conocimiento-práctica de la diversidad de pesquerías, entre el polo de las más tecnificadas y el de las de pequeña escala (ver Florido, 2008, para su identificación socioeconómica). 
Me estoy refiriendo a un saber-hacer, incorporado, práctico, sensorial (Florido, 2018), pero que lleva implícita una "teoría", una visión de las relaciones humano-ambientales, por lo que no es acertada la oposición entre saber científico-objetivo-representacional del mundo y saber vernáculo de carácter pragmático. Las traducciones entre el mar "del" que se habla y la mar "en" que se habla existen y deben expandirse.

¿En qué medida este tipo de saberes puede tener una plasmación en contextos políticos y económicos contemporáneos?

\section{La vertiente política de las hibridaciones}

La gestión de los ecosistemas marinos se ancla en un dispositivo, en el sentido foucaultiano (Heredia, 2014). ${ }^{20}$ Este dispositivo es participado tanto por organizaciones y discursos de las ciencias biológica y económica marinas (la denominada bioeconomía), como por parte del Estado, en la diversidad de sus expresiones institucionales. Se ha ido afianzando a lo largo del siglo XX, desarrollando los principios que Latour (2005) denomina las tres diosas unidas: la Eficacia (técnica), la Rentabilidad (económica), y la Objetividad (científica).

"La mar no es infinita, como el horizonte, sino que nosotros pescamos en determinadas zonas", advertía el representante de los pescadores artesanales de Chipiona (Cádiz) en una reunión mantenida recientemente con científicos y otros pescadores para referirse a que las medidas de gestión deben realizarse contando con sus prácticas y su conocimiento sobre el territorio. Es decir, hay una relación de apropiación del

20 Red de elementos heterogéneos (instituciones, discursos, prácticas), cuya vocación es establecer un orden en un contexto socioterritorial específico, dentro de un marco histórico, a partir de la eclosión de una problemática que se quiere atajar desde las instancias con poder. El quién es un elemento importante, pues Foucault rehúsa pensar en una agencia omnisciente, ni individualizada, sino más bien en el resultado colaborativo de agentes diversos, desde campos distintos pero complementarios, "un conjunto disperso de invenciones, de microdispositivos" que logran el diseño de un esquema metacultural (Heredia, 2014, p. 88). territorio, a la par material y cognitiva, que deviene clave para cualquier política de gestión de recursos. ¿De qué manera los modos de ser-saber-hacer de los pescadores pueden posicionarse políticamente, en un espacio donde conviven con sistemas de conocimiento científico que sirven para legitimar las medidas de gestión? A la luz de las reflexiones previas, parece claro que los sistemas relativamente autónomos de conocimiento sobre el medio marino deben encontrarse en lo que Callon definió como un "punto de paso obligado" (1995, p. 265), un espacio de traducción, de diálogo, de trasvase, entre científicos, pescadores y funcionarios. Pues el objetivo es común: favorecer la continuidad de los socioecosistemas marinos. Como bien supo destacar el representante de la flota artesanal del Chipiona en uno de los encuentros entre pescadores, científicos, políticos y ONG, todo estudio científico se basa en la información que aporta el marinero en el barco, por tanto, es fundamental que el pescador "sienta la corresponsabilidad" para poder llegar a poner en común esas tradiciones. Solo de este modo se podrá construir un nuevo "agenciamiento colectivo de enunciación” (Deleuze y Guattari, 2004, p. 13), en el que participen tanto unos como otros.

Ya no se trata de oponer el modo bricoleur de LéviStrauss -caracterizado por juntar elementos heterogéneos, que pertenecen a regímenes distintos y presuntamente incompatibles- al de ingeniero -quien utiliza los medios necesarios para ejecutar un plan previo-, aquel representado por el pescador, este por el saber científico. Lo que urge lograr es la emergencia de un modo bricoleur de más amplio alcance, que dé cobertura al saber científico y al vernáculo, no dando prelación a priori a ninguno de ellos, sino seleccionando puntos de convergencia y divergencia que ayuden a un esclarecimiento continuo de las dinámicas socioecosistémicas. Merece el esfuerzo promover su "co-laboración", su traducción, siguiendo un modelo antes rizomático que jerárquico. Quiero reivindicar aquí la dimensión fronética de la que habla Aristóteles en el Libro VI de la Etica a Nicómaco, tradicionalmente desconsiderada en la tradición de teorías occidentales del conocimiento, al menos desde la Modernidad. La "phronesis" hace referencia al "saber hacer", a la prudencia que el actor adquiere con la experiencia, la intuición, y que rige éticamente sus comportamientos -ese "sentir 
la responsabilidad"-, según valores que se han ido constituyendo en tradición (Linke y Jentoft, 2014). Esta dimensión subsiste entre los pescadores. Pero el pescador no puede ser desculturalizado, ni naturalizado, como un actor racionalista maximizador sin más. La incorporación de los pescadores a los procesos de discusión y toma de decisiones para regular los usos y actividades en el territorio marino incrementa la legitimidad del proceso normativo (Berkes, 2009; Herrera-Racionero, Lizcano-Fernández y Miret-Pastor, 2015), además de posibilitar un mayor grado de corresponsabilidad. Mi experiencia en los foros de encuentro entre representantes de pescadores, de la Administración y científicos es que el pescador aprende, se familiariza con los razonamientos de planificadores y científicos, con los que puede entablar un diálogo -no exento de dificultades- y pasa a dejar de considerarlos como "otros", frente a los que construye una imagen de sí mismo, para justificar por qué no está dispuesto a aplicar las normas que entiende como "impuestas" y, aún peor, definidas por quienes -refiriéndose en especial a los técnicos de la Administración - no conocen "a través de" la práctica los entresijos de la mar. En sentido contrario, las discusiones que se producen en estos foros tienen el doble efecto de generar, restaurándolos incluso, lazos comunitarios de corresponsabilidad (Jentoft, 2000) y la comprensión, por parte de los técnicos, de las razones pragmáticas por las que algunas normas son mejorables. Ello no quiere decir que el sistema vaya a ser cambiado, pero sí que se crea la oportunidad política de que se sometan a consideración y que exista la posibilidad de transformar algunas de las normas. ${ }^{21}$

El drama de las culturas (saber hacer, saber decir, saber sentir) de los pescadores es que muchos de sus hábitos interpretativos, clasificatorios, metafóricos,

21 Ha sido esta mi experiencia en el caso de la pesquería del pulpo en el frente atlántico de Andalucía, que ha dado lugar a una nueva norma reguladora del gobierno regional resultado de un proceso consultivo muy amplio, Orden de 25 de abril de 2017, por la que se regula la captura de pulpo (Octopus vulgaris) con artes específicos en el caladero nacional del golfo de Cádiz y se crea el Censo de embarcaciones autorizadas para dicha actividad; o el caso de normas concretas relativas a artes de pesca, censo y horarios en el caso de la Reserva de Pesca del Guadalquivir, actualmente en proceso de revisión. no pueden tener una expresión en los dispositivos políticos, porque las presiones políticas, tecnológicas y del mercado inciden de modo directo en el metabolismo cultural de sus hábitos. Frente a un modelo relacional, indiciario, en revisión permanente, anclado en la práctica de su modo de conocer, se encuentra un esquema jerárquico, el científico, que trata sus modelos como representaciones reales del mundo natural -entendido este como esfera independiente- y en los que los pescadores no son considerados como actantes dentro de los ecosistemas. Se da por descontado que el pescador es una función: un actor maximizador, instrumentalmente racional(ista), "ceteris paribus", porque así (se piensa que) es, no su cultura, sino su naturaleza.

\section{Hibridaciones económicas en el Pacífico Sur (Chile)}

Para responder a las repercusiones de hibridaciones culturales en el ámbito económico, existe bibliografía sobre el papel de modos artesanales de extracción en ecosistemas marinos en el sur de Chile y sobre las contradictorias relaciones que mantienen tanto con culturas productivas existentes como con procesos de globalización económica en la zona. Al primer tipo pertenece el estudio de Gajardo y Ther (2011), quienes identifican los procesos de aprendizaje entre campesinos y pescadores que se combinan en la costa occidental de Chiloé (caleta de Guabún), para facilitar nuevas prácticas de aprovechamiento del borde costero en relación con el marisqueo y la pesca. Estas transacciones generaron nuevas actitudes para dinamizar tanto la gestión del territorio -pues existen tensiones resultado de la competencia por poblaciones de peces entre distintos grupos de pescadores- como los intercambios económicos. Los mismos pescadores del norte que provocan las tensiones son los que facilitan procesos de aprendizaje y de patrimonialización del borde costero sobre valores característicos de las comunidades campesinas por parte de los habitantes de Guabún (Gajardo y Ter, 2011, p. 594). En el caso de Puñihuil las transacciones y aprendizajes se produjeron entre prácticas extractivas (incluyendo buceo) y otras actividades de servicios turísticos (visitas a pingüineras), más ligadas a procesos de mercantilización, en el marco de un área de manejo, impulsada por 
agentes externos, procedentes del norte. La cultura de incesantes movimientos migratorios para desplazarse por el borde costero con equipos de pesca y buceo se ha mantenido, extendiéndose hacia otras zonas de Chiloé (Gajardo y Ter, 2011, p. 597). Con estos desplazamientos viajan prácticas y saberes, que se van entrecruzando con las que se encuentran en los distintos hábitats ya ocupados, socioecosistemas que van ganando, por tanto, en complejidad. La diversidad de estrategias con las que los pescadores artesanales van aprovechando las posibilidades de los ecosistemas costeros se mantiene cuando nuevas actividades aparecen, como en la llamada "fiebre del loco" (años ochenta), o con la irrupción del régimen industrial de las salmoneras (desde los noventa a la actualidad). Progresivamente, el socioecosistema se va ampliando, incorporando a mujeres y miembros más jóvenes de las unidades domésticas en campos y playas cercanas, mientras que los hombres navegan a lugares más alejados conforme las poblaciones de peces y moluscos se van agotando y moviéndose, $\mathrm{y}$ se ajustan en estrategias y territorio cuando se trata de convivir con el turismo, "estilos de vida que paradójicamente se han mostrado como complementarios" (Gajardo y Ther, 2011, p. 599), como ya había sucedido con el modo campesino en la zona de Guabún.

En todo el mar interior chilote, con la llegada de la salmonicultura, los pescadores se incorporan a distintas actividades en la cadena de trabajo de las instalaciones, injertando este trabajo estacional al patrón de migraciones estacionales que ya caracterizaba a las culturas de trabajo de los pescadores artesanales chilotes (Barton y Román, 2016). La modernización, por tanto, no aniquila necesaria ni completamente saberes, prácticas o valores tradicionales -siendo sustituidos entonces por ingenierías modernas-, sino que puede ser un campo de hibridación que dé lugar a distintas formas de reconstitución del escenario económico. Así, Saavedra y Macías (2016) entienden que los saberes vernáculos de miticultores chilenos pueden tener una funcionalidad en la cadena de producción de valor si se ponen en marcha estrategias adecuadas. En el mismo sentido, el avance de fórmulas capitalistas en la organización empresarial de la salmonicultura industrial en la Patagonia insular occidental, y los valores a ellas asociados, no ha eliminado los sistemas de vida locales, previamente asentados. Estos se reconfiguran, y todavía pueden cumplir funciones clave en el establecimiento de las nuevas empresas asociadas a la acuicultura (Barton y Roman, 2016; Saavedra, Mardones y Torres, 2016).

Específicamente, Saavedra argumenta que el desarrollo de la salmonicultura en el sur de Chile, paradigma de la progresiva penetración de un metabolismo industrial en las relaciones humano-ambientales de los ecosistemas costeros, se comprende mejor atendiendo a las contribuciones de los saberes de pescadores artesanales (tanto pescadores marinos como miticultores y recolectores de algas), ya asentados en la zona. En particular, destaca su saber hacer en su relación con el entorno físico, en el borde costero y en el espacio submarino, a pesar de que los discursos crecentistas y desarrollistas dominantes lean este complejo marco de relaciones de modo inverso, como subraya Escobar (2010); es decir, señalando que las ingenierías modernas rescatan a las comunidades tradicionales de su estancamiento. Desde este punto de vista, estos tejidos socioculturales tradicionales no pueden entenderse de modo restringido como contribuciones a la reproducción del capital industrial, comercial y financiero que se asienta en la zona de la mano del complejo salmonero. Si bien es cierto que el avance de este complejo implica transformaciones drásticas y degradación en las condiciones ecosistémicas (Niklitschek, Soto, Lafon, Molinet y Toledo. 2013), así como una alteración abrupta de formas de vida asentadas y basadas en un modelo doméstico artesanal (Mansilla, 2007), han de ser reconocidas dinámicas de hibridación en el emergente complejo salmonero (Barton y Roman, 2016). Así, una parte del acervo de saberes vernáculos se ha incrustado en el sistema industrial creando servicios y relaciones laborales nuevas (por ejemplo, los buzos mariscadores empleados en las granjas acuícolas), especialmente en la región de Aysén (Saavedra et al., 2016). Complementariamente, la extracción de especies tradicionales, como el erizo, se destinan mayoritariamente a la exportación internacional, poniendo de manifiesto las incertidumbres ecológicas que han de afrontar, también, las formas de extracción denominadas "artesanales". Ther ha destacado cómo en un contexto de modernización en el maritorio chilote, se constata una diversidad de rutas y usos entre distintos tipos 
de agencias: las más periféricas han pervivido gracias a los reservorios de memorias de los pescadores artesanales, que las siguen usando, "aun cuando la tecnologización de la pesca ha provocado profundas brechas entre los medianos y los pequeños pescadores" (Ther, 2011, p. 74).

\section{Conclusión}

En definitiva, cabe asumir que las sociedades son resultado de procesos globales y locales que se articulan y se constituyen mutuamente, como reclamaba E. Wolf (1984).22 Ello nos debe evitar un análisis dualista y esencialista según el cual las relaciones culturales se reducen a una confrontación Nosotros/ Otros, Occidente/Resto, Mercado/Otras racionalidades ("capitalismo" u "occidente", frente a "sociedades precapitalistas", "comunidades indígenas", etc.) (Bird-David, 1997). El acercamiento etnográfico parece el modo de trabajo más adecuado para una antropología más simétrica y que saque a flote los saberes-prácticas silenciados (Santos, 2006), que sospeche de los modelos formales de la ciencia occidental y los ubique como productos culturales a revisar y con los que dialogar; una antropología más apegada a los mundos de vida de la gente que reproducen racionalidades variopintas: llegar a comprender la diversidad cultural para entender la diversidad de formas económicas, y viceversa.

La "ecología de saberes" de Boaventura de Sousa Santos (2006) nos orienta para superar las fronteras entre modos de conocimiento, con una visión integradora que supere las escisiones de esta pluralidad y recupere el abismo al que han estado sometidos esos otros modos de saber-hacer. En el campo de

22 "Lo que sostengo es que, en la mayoría de los casos, las entidades estudiadas por los antropólogos deben su desarrollo a procesos que se originan en su exterior, lejos de su alcance, que deben su cristalización a estos procesos, participan en ellos, y que también ellas, a su vez, afectan a estos desarrollos y procesos. Designaciones tales como Ojibwa, Iroqueses [...] Zulú y Tswana se configuran dentro de un amplio campo social y cultural en el que participaron viajeros, comerciantes de esclavos, caballerías, jesuitas, agentes de la Hudson's Bay Company y otros. Las 'cult-unidades' de la antropología no precedieron la expansión del comercio y del capitalismo, sino que surgieron y se diferenciaron en el curso de la misma” (Wolf, 1984, pp. 395-396). la pesca ya hay una tradición que reivindica esta colaboración entre distintos modos de saber (Neis et al., 1999). Es una propuesta que, políticamente, reivindica la simetría, al menos hasta llegar a las primeras conclusiones de un análisis compartido. Como destaca Blaser (2009) en relación a una comunidad de pescadores de Paraguay, no es posible plantear un debate ni teórico ni político sobre la problemática de los ecosistemas marinos, si no es atendiendo a cuál(es) es(son) la(s) perspectiva(s) cultural(es) de los grupos humanos en cuestión, siendo un aspecto clave de esta visión sus nociones de naturaleza y de las relaciones que mantienen los seres humanos con esa heterogeneidad de interacciones que homogeneizamos y alienamos (en el sentido de exteriorizar) con el rubro "naturaleza", pero que bien podríamos denominar 'culturalezas'. Mi propia experiencia, en los procesos de participación al que venimos asistiendo desde 2015 en algunas pesquerías del Golfo de Cádiz, me permite asegurar el mutuo enriquecimiento entre modos de conocimiento. En el caso chileno, las etnografías de autores como Gajardo y Ther atestiguan la combinación de técnicas de pesca y de buceo que permite a los pescadores chilotes un prolijo conocimiento de los fondos marinos. Ello les posibilita experimentar y trasladar ese saber hacer a sus tácticas territoriales y de pesca, expresando ese saber-hacersentir "comunitario" y"relacional" que quedó explicado en el caso andaluz. De lo que se trata es de "potenciar estrategias que incluyan este tipo de conocimientos; se requieren estudios sobre el conocimiento ecológico local del fondo marino, lo cual estimamos contribuiría tanto a la diversificación de las AMERB [Áreas de Manejo y Explotación de Recursos Bentónicos] como también enriquecería el conocimiento preciso sobre los fondos marinos, sus usos y dinámicas" (Gajardo y Ther, 2011, p. 600). Es decir, el manejo de socioecosistemas puede obtener de aquí enormes potencialidades, si se adopta precisamente una óptica local en un marco institucional de reconocimiento y responsabilidad compartidos entre los distintos actores.

A finales de los años setenta, Edgar Morin reclamaba la construcción de un nuevo método científico basado en el encuentro de la "physis" (medio físico y su expresión biológica) y la antropo-sociología. Ambos llegarían a ser "co-productores el uno del otro", 
para así lograr un "doble enraizamiento teórico en la 'naturaleza' y en la 'cultura', en el 'objeto' y en el sujeto” (Morin, 1986, p. 314). Veinte años más tarde, Berkes y Folke (1997) reclamaban un modelo de gestión de relación, desde dentro de los ecosistemas, que superase las fallas de los modelos bioeconómicos, que consideraban poblaciones monoespecíficas como "recursos" o utilidades, aislables de sus entornos. Complementariamente, propugnaban profundizar en conocimientos e instituciones de poblaciones humanas, prácticas y saberes con los que las sociedades han tratado históricamente de relacionarse con otras poblaciones (no humanas), coadyuvando a las regulaciones de sus transacciones. He tomado este hilo para construir una reflexión sobre material etnográfico recolectado en las costas andaluzas, además de sobre análisis de antropología económica en el sur de Chile, todo ello tamizado desde una perspectiva en la que los conceptos claves son la relacionalidad y las hibridaciones en los modos de hacer y pensar de los pescadores. Su última aspiración es promover un análisis en el que se muestre la íntima conexión existente entre la diversidad biológica y la diversidad cultural, desde una perspectiva integradora, tal y como lo demanda Diegues (2000, p. 165) para el caso de Brasil. El objetivo práctico es que pueda suscitar nuevas aplicaciones en otros contextos geoculturales.

\section{Agradecimientos}

Este trabajo se nutre principalmente de la etnografía realizada durante sucesivas investigaciones financiadas por la Organización World Wild Fund for Nature: "Diagnóstico pesquero en la gestión de los recursos marinos en el frente del PN Dońana" (2015-2016), llevadas a cabo, con nuestra colaboración, por la Sociedad para el Desarrollo de las Comunidades Costeras; y "Seguimiento y Mejora de las Pesquerías del Golfo de Cádiz" (2016-2018), con distintas líneas de actuación. Quiero agradecer a todos los pescadores que han querido trasladar a la superficie del discurso una parte de un saber hacer que está tan incorporado y que no siempre es fácil de verbalizar. Asimismo, a Inmaculada Martínez por realizar el material cartográfico, a Juan Ruiz por aportar material fotográfico, a Gonzalo Saavedra por realizar aportaciones a un primer manuscrito y a Laura Mora por revisarlo.

\section{Referencias citadas}

Álvarez de Toledo, L. I. (2007). Las almadrabas de los Guzmanes. Sanlúcar de Barrameda: Fundación Casa Medina Sidonia.

Barton, J. y Román, A. (2016). Sustainable development? Salmon aquaculture and late modernity in the archipelago of Chiloé, Chile. Island Studies Journal, 11(2), 651-672.

Berkes, F. (2009). Evolution of co-management: role of knowledge generation, bridging organization and social learning. Journal of Environmental Management, 90, 1692-1702.

Berkes, F. y Folke, C. (1997). Linking Social and Ecological Systems. Management Practices and Social Mechanisms for Building Resilience. Cambridge, MA: Cambridge University Press.

Bird-David, N. (1997). Economies: a cultural-economic perspective. International Social Sciencie Journal, 49 (154), 463-475.

Blaser, M. (2009). The Threat of the Yrmo: The Political Ontology of a Sustainable Hunting Program. American Anthropologist, 111(1), 10-20.

Callon, M. (1995). Algunos elementos para una sociología de la traducción: la domesticación de las vieiras y los pescadores de la bahía de St. Brieuc. En Iranzo et al. (Comps.). Sociología de la ciencia y la tecnología (pp. 259282). Madrid: CSIC.

Clark, A. (1999). Estar ahi. Cerebro, cuerpo y mundo en la nueva ciencia cognitiva. Madrid: Paidós Ibérica.

De Sousa Santos, B. (2006). Renovar la teoría crítica y reinventar la emancipación social. Buenos Aires: CLACSO. Deleuze, G. y Guattari, F. (2004). Mil Mesetas. Capitalismo y esquizofrenia. Valencia, España: Pre-Textos.

Dennet, D. (1996). Kinds of Minds. New York: Basic Books.

Descola, Ph. (1988). La selva culta: Simbolismo y praxis en la ecología de los Achuar. Quito: Ediciones Abya-Yala e Institut Français d'Études Andines.

Descola, Ph. (2011). Más allá de la naturaleza y la cultura. En Montenegro Martínez, L. (Ed.). Cultura y Naturaleza (pp. 75-97). Bogotá: Jardín Botánico de Bogotá, JCM. 
Descola, Ph. [2005] (2012). Más allá de la naturaleza y la cultura. Buenos Aires: Amorrortu.

Diegues, A. (2000). El mito moderno de la naturaleza intocada. Quito: Abya-Yala.

Douglas, M. (2008). Estilos de pensar: ensayos críticos sobre el buen gusto. Barcelona: Gedisa.

Escobar, A. (1999). After Nature. Steps towards an Antiessentialist Political Ecology. Current Anthropology, 40(1), 1-30.

Escobar, A. (2010). Una minga para el posdesarrollo: Lugar, medio ambiente y movimientos sociales en las transformaciones globales. Lima: Universidad Nacional Mayor de San Marcos.

Friedman, J. (1996). Identidad cultural y proceso global. Buenos Aires: Amorrortu.

Florido del Corral, D. (2002). Los sentidos y el saber hacer de los pescadores andaluces. Demófilo, Revista de Cultura Tradicional, Tercera Época, 1, 139-156.

Florido del Corral, D. (2008a). Las flotas artesanales andaluzas en un contexto de crisis. En González-Laxe, F. (Ed.). Lecciones de Economía Pesquera (pp. 267-297). A Coruńa, España: Instituto de Estudios Marítimos, Netbiblo.

Florido del Corral, D. (2008b). Vigor crítico y minusvalía política: las impotencias del discurso antropológico en la política pesquera. En Jabardo, M., Monreal, P. y Palenzuela, P. (Coords.). Antropología de Orientación Pública: Visibilización y Compromiso de la Antropología (pp. 171191). Donosti, España: Ankulegi y Federación de Asociaciones de Antropología del Estado Español.

Florido del Corral, D. (2014). Los corrales de pesca en la provincia de Cádiz: usos y apropiaciones en torno a un paisaje cultural. XIII Congreso de Antropología de la FAAEE. Periferias, Fronteras y Diálogo (pp. 2935-2958). Tarragona, Espańa: Universidad Rovira i Virgili.

Florido del Corral, D. (Coord.) (2017). Las almadrabas suratlánticas andaluzas. Historia, Tradición y Patrimonio (ss. XVIII-XXI). Sevilla: Servicio de Publicaciones de la Universidad de Sevilla.

Florido del Corral, D. (2018). What it takes to be the captain of a Tuna Trap: Practice, Knowledge and skills for the sustainability of an age-old mode of fishing. In $A n$ dalusia: History, Society and Diversity (pp. 29-55). Nueva York: Nova Science Publisher.

Florido, D. y Maya-Jariego, I. (2018). Secreto y conocimiento ecológico tradicional sobre el medio marino en la Reserva de Pesca de la Desembocadura del Guadalquivir. En Antropología Ambiental. Conocimientos y Prácticas Locales a las Puertas del Antropoceno (pp. 173-199). Barcelona: Icaria.

Gajardo Cortés, C. y Ther Ríos, F. (2011). Saberes y prácticas pesquero-artesanales: cotidianeidades y desarrollo de las caletas de Guabún y Puñihuil, Isla de Chiloé. Chungara. Revista de Antropología Chilena, 43(1), 589-605.

Galván, A. y Pascual, J. (2016). Las sociedades de pescadores y la antropología. En Müllauer-Sachter, W. (Ed.). Claves en los inicios de la Antropologia Social y Cultural española (pp. 243-255). Madrid: UNED.

García Calvo, A. (1979). Del lenguaje. Madrid: Lucina.

García Canclini, N. (1990). Culturas hibridas. Estrategias para entrar y salir de la Modernidad. México, DF: Grijalbo.

Gudeman, S. (2001). The Anthropology of Economy. Oxford: Blackwell Publishers.

Haraway, D. (2016). Manifiesto de las especies de compañia. Vitoria, España: Sans Soleil.

Heredia, J. M. (2014). Dispositivos y/o agenciamientos. Contrastes. Revista Internacional de Filosofía, XIX(1), 83-101.

Herrera-Racionero, P., Lizcano-Fernández, E. y MiretPastor, Ll. (2015). "Us" and "them". Fishermen from Gandía and the loss of institutional legitimacy. Marine Policy, 54, 130-136.

Holbraad, M. (2014). Tres provocaciones ontológicas. Ankulegi, 18, 127-139.

Jentoft, S. (2000). The Community. A Missing Link of Fisheries Management. Marine Policy, 24, 53-59.

Latour, B. (1992). La ciencia en acción. Barcelona: Labor.

Latour, B. (2005). Llamada a revisión de la Modernidad. Aproximaciones antropológicas. AIBR, Revista de Antropología Iberoamericana, Número Especial Nov-Dic, 1-21. 
Law, J. y Mol, A. (1995). Notes on Materiality and Sociality. The Sociological Review, 43, 274-294.

Leff, E. (2014). La apuesta por la vida. México, DF: Siglo XXI.

Linke, S. y Jentoft, S. (2014). Exploring the phronetic dimension of stakeholders' knowledge in EU fisheries governance. Marine Policy, 47, 153-161.

Mansilla, S. (2007). Hay un dios que todo lo compra: Identidad y memoria de Chiloé en el siglo XXI. Revista Austral de Ciencias Sociales, 12, 145-158.

Maturana, H. y Varela, F. (1987). The Tree of Knowledge. Berkeley: Shambhala.

Morin, E. (1986 [1977]). El Método. La naturaleza de la naturaleza. Madrid: Cátedra.

Neis, B., Felt, L., Haedrich, R. y Schneider, D. (1999). An interdisciplinary methodology for collecting and integrating fishers' ecological knowledge into resource management. En Newell, D. y Ommer, R. (Eds.). Fishing places, fishing people: issues in Canada small-scale fisheries (pp. 217-238). Toronto: University of Toronto Press.

Niklitschek, E., Soto, D., Lafon, A., Molinet, C. y Toledo, P. (2013). Southward expansion of the chilean salmon industry in the Patagonian fjords: main environmental challenges. Reviews in Aquaculture, 4, 1-24.

Pálsson, G. (2001). Relaciones humano-ambientales. Orientalismo, paternalismo y comunalismo. En Descola, Ph. y Pálsson, G. (Coords.). Naturaleza y sociedad. Perspectivas antropológicas (pp. 80-100). México: Siglo XXI.

Saavedra Gallo, G. y Macías Vázquez, A. (2016). Collective action and symbolic capital in the artisanal fisheries: An analysis of the Local Food Systems of Reloncaví Estuary
(Los Lagos), Chile. Culture and History Digital Journal, 5(1), 1-13.

Saavedra Gallo, G., Mardones Leiva, K., y Torres Zamora M. P. (2016). La esquizofrenia del desarrollo: Un análisis semántico-discursivo de las relaciones entre salmonicultura y pesca artesanal en el sur-austral de Chile. Cuhso. Cultura-Hombre-Sociedad, 26(2), 71-105.

Sánchez-Fernández, J. O. (1992). Ecología y estrategias sociales de los pescadores de Cudillero (Asturias). Madrid: Siglo XXI.

Sáñez Reguart, A. (1791-95). Diccionario de las Artes de Pesca Nacional. V vols. Madrid: Viuda de Ryvadeneira.

Soper, K. (1996). "Nature/'nature”. En Robertson, G. et al. (Eds.). Future Natural (pp. 22-34). London: Routledge,

Ther, F. (2011). Configuraciones del tiempo en el mar interior de Chiloé y su relación con la apropiación de los territorios marítimos. Desenvolvimento e Meio Ambiente, 23, 67-80.

Thoreau, H. D. (2005 [1854]). Walden. Madrid: Cátedra.

Tirado Serrano, F. y Domènech i Argemi, M. (2005). Asociaciones heterogéneas y actantes: el giro post-social de la teoría del actor-red. AIBR, Revista de Antropología Iberoamericana, Especial Nov-Dic., 1-27.

Varela, F., Thompson, E. y Rosch, E. (1992). El cuerpo presente. Las ciencias cognitivas y la experiencia humana. Barcelona: Gedisa.

Vega Encabo, J. (2005). Mentes híbridas: Cognición, representaciones externas y artefactos epistémicos. AIBR, Revista de Antropología Iberoamericana, Número Especial Nov-Dic., 1-36.

Wolf, E. (1984). Culture: Panacea or Problem? American Antiquity, 49(2), 393-400. 